\title{
A coupled observation - modeling approach for studying activation kinetics from measurements of $\mathrm{CCN}$ activity
}

\author{
T. Raatikainen ${ }^{1}$, R. H. Moore ${ }^{2, *}$, T. L. Lathem ${ }^{1}$, and A. Nenes ${ }^{1,2}$ \\ ${ }^{1}$ School of Earth and Atmospheric Sciences, Georgia Institute of Technology, Atlanta, Georgia, USA \\ ${ }^{2}$ School of Chemical and Biomolecular Engineering, Georgia Institute of Technology, Atlanta, Georgia, USA \\ *currently at: NASA Langley Research Center, Hampton, VA, USA
}

Correspondence to: A. Nenes (athanasios.nenes@gatech.edu)

Received: 7 January 2012 - Published in Atmos. Chem. Phys. Discuss.: 19 January 2012

Revised: 22 April 2012 - Accepted: 23 April 2012 - Published: 11 May 2012

\begin{abstract}
This paper presents an approach to study droplet activation kinetics from measurements of $\mathrm{CCN}$ activity by the Continuous Flow Streamwise Thermal Gradient CCN Chamber (CFSTGC) and a comprehensive model of the instrument and droplet growth. The model, which can be downloaded from http://nenes.eas.gatech.edu/Experiments/ CFSTGC.html, is evaluated against a series of experiments with ammonium sulfate calibration aerosol. Observed and modeled droplet sizes are in excellent agreement for a water vapor uptake coefficient $\sim 0.2$, which is consistent with theoretical expectations. The model calculations can be considerably accelerated without significant loss of accuracy by assuming simplified instrument geometry and constant parabolic flow velocity profiles. With these assumptions, the model can be applied to large experimental data sets to infer kinetic growth parameters while fully accounting for water vapor depletion effects and changes in instrument operation parameters such as the column temperature, flow rates, sheath and sample flow relative humidities, and pressure. When the effects of instrument operation parameters, water vapor depletion and equilibrium dry particle properties on droplet size are accounted for, the remaining variations in droplet size are most likely due to non-equilibrium processes such as those caused by organic surface films, slow solute dissociation and glassy or highly viscous particle states. As an example of model application, data collected during a research flight in the ARCTAS 2008 campaign are analyzed. The model shows that water vapor depletion effects can explain changes in the observed average droplet size.
\end{abstract}

\section{Introduction}

Aerosols are the precursors of cloud droplets and can profoundly affect cloud albedo, lifetime, and droplet size distribution. Aerosol-cloud interactions have important impacts on global climate, but with a magnitude that is considerably uncertain (IPCC, 2007). Clouds are formed by cooling of humid air masses (often in a rising thermal) that eventually become supersaturated and activate cloud droplets on preexisting aerosol. Subsaturated growth occurs in equilibrium with the ambient relative humidity, but growth and activation under supersaturated conditions are kinetically limited by the availability of water vapor and gas- and aerosol-phase mass transfer resistances (e.g. Chuang et al., 1997; Nenes et al., 2001). Consequently, droplet growth rates can be affected by delays in solute dissolution (Asa-Awuku and Nenes, 2007), formation of organic surface films (Chuang, 2003) and, possibly, glassy aerosol states (Zobrist et al., 2008; Virtanen et al., 2010; Tong et al., 2011; Koop et al., 2011). Delays in droplet growth kinetics have a tendency to decrease average cloud droplet size for a given growth period; if occurring for all cloud condensation nuclei (CCN) in the updraft, cloud droplet number concentration is promoted by allowing higher maximum supersaturation values to be reached since water vapor is not removed to the aerosol phase as quickly (Nenes et al., 2002).

The supersaturated droplet growth depends on diffusion limited transport of water vapor to the surface, but also on transport through the droplet surface and bulk solution (Davidovits et al., 2006; Kolb et al., 2010). The likelihood of adsorption and subsequent absorption can be described by the 
mass accommodation coefficient or the effective uptake coefficient $\left(\alpha_{\mathrm{c}}\right)$ which includes the other resistances. For ideal liquid water droplets, collision of a vapor molecule leads almost always to adsorption, so that water droplet growth depends only on the diffusion of water vapor. The situation can become more complicated when solutes are present in the aqueous phase as they may change the bulk solution equilibrium state and the droplet surface properties.

Different values have been suggested for $\alpha_{\mathrm{c}}$ (e.g. Mozurkewich, 1986; Shaw and Lamb, 1999; Li et al., 2001; Davidovits et al., 2004; Zientara et al., 2005; Winkler et al., 2004, 2006; Kolb et al., 2010), but the converging view is that it is close to unity $(\geq 0.1)$ for water surfaces. Several theoretical and experimental techniques are used to study water uptake (Davidovits et al., 2006; Kolb et al., 2010). Molecular dynamics simulations (e.g. Bahadur and Russell, 2008; Takahama and Russell, 2011) offer a first principles approach for estimating $\alpha_{\mathrm{c}}$ and understanding the processes of adsorption and absorption of water vapor into the growing droplets. Experiments are usually droplet growth or evaporation studies where observations are interpreted by a suitable numerical model. Both sub-saturated (e.g. Chuang, 2003, 2006; Sjogren et al., 2007; Drisdell et al., 2009; Tong et al., 2011) and supersaturated (e.g. Winkler et al., 2004, 2006; Ruehl et al., 2008, 2009; Lance et al., 2009; Asa-Awuku et al., 2009, 2010; Shantz et al., 2010) conditions have been used. Most of the latter are done with $\mathrm{CCN}$ instruments such as the Droplet Measurement Technologies (DMT) CCN counter (Lance et al., 2006), which is based on the Continuous Flow Streamwise Thermal Gradient Chamber (CFSTGC) design (Roberts and Nenes, 2005).

CCN activation kinetics can be qualitatively studied by the threshold droplet growth analysis (TDGA) technique, where measured droplet sizes are compared against those from calibration experiments (Moore et al., 2008; Engelhart et al., 2008). To account for hygroscopicity and dry size differences between aerosol, both droplet sizes are selected from the point where activation is first observed. TDGA has been applied to several ambient aerosol samples (AsaAwuku et al., 2011; Bougiatioti et al., 2009, 2011; Lance et al., 2009; Murphy et al., 2009; Padró et al., 2010, 2011; Cerully et al., 2011), secondary organic aerosol (SOA) (Engelhart et al., 2008, 2011; Asa-Awuku et al., 2009, 2010) and laboratory-generated aerosol (Moore et al., 2008; Kumar et al., 2011a,b). In general, slower kinetics than calibration aerosol have been related to insoluble organics from SOA chamber experiments (Asa-Awuku et al., 2009), fresh exhaust plumes (Murphy et al., 2009), and mineral dust particles when using a dry generation technique (Kumar et al., 2011a,b). Ruehl et al. (2008, 2009) have also found slowly growing particles in a number of environments using a CFSTGC with a Phase Doppler Interferometer as the droplet detector.

There are some important limitations with TDGA. First, droplet size does not depend only on the water vapor up- take coefficient, but also on instrument operation parameters (e.g. supersaturation, temperature, pressure and flow rates), aerosol properties (e.g. hygroscopicity and size distributions), and CCN concentration. Water vapor depletion in the instrument from high $\mathrm{CCN}$ concentrations leads to decreases in the instrument supersaturation and final droplet size (Lathem and Nenes, 2011). CCN concentrations are not significantly affected, but even moderate particle concentrations can have an observable effect on droplet size (Lathem and Nenes, 2011). The second limitation of TDGA is that it cannot provide numerical values for vapor uptake coefficients; a droplet growth model such as those used by Shantz et al. (2010), Ruehl et al. (2008, 2009), Asa-Awuku et al. (2009) and Kumar et al. (2011a) is instead required.

Here we present an approach to study droplet activation kinetics and quantify kinetic parameters from measurements of CCN activity combined with a comprehensive model of the process. For the latter, an augmented version of the coupled DMT CCN instrument and droplet growth model used previously in Roberts and Nenes (2005), Lance et al. (2006), and Lathem and Nenes (2011) is developed and applied. Model accuracy is assessed by a comprehensive series of droplet growth experiments with ammonium sulfate calibration aerosol. A careful calibration of the optical particle counter is carried out to quantify sizing uncertainty and the sheath flow relative humidity is measured to provide an accurate model for inlet boundary conditions. Sources of prediction uncertainty in the model are explored. Simplifying assumptions, which do not introduce significant prediction errors, are introduced to accelerate calculations. The accelerated model is able to simulate droplet growth for large CCN data sets collected from field campaigns and laboratory experiments. We demonstrate this using an airborne CCN sample data set collected in the vicinity of intense biomass burning plumes during the 2008 ARCTAS experiment.

\section{Simulating $\mathrm{CCN}$ activation and growth}

The analysis here focuses on the Droplet Measurement Technologies (DMT) Continuous Flow Streamwise Thermal Gradient CCN chamber (Roberts and Nenes, 2005; Lance et al., 2006), although the approach presented here can be applied to any $\mathrm{CCN}$ instrument. A simple scaling analysis can be performed to unravel the dependence of growth kinetics on instrument operation conditions (Appendix A). However, depletion effects and other sources of variability cannot easily be accounted for by such an approach; this necessitates a comprehensive modeling approach.

Droplet growth kinetics are simulated using a Lagrangian approach that tracks individual particles as they flow through the instrument. An Eulerian approach is used to predict the distributions of supersaturation, temperature, pressure and velocities from the known flow rate, humidity and temperature boundary conditions. The droplet and gas (including 


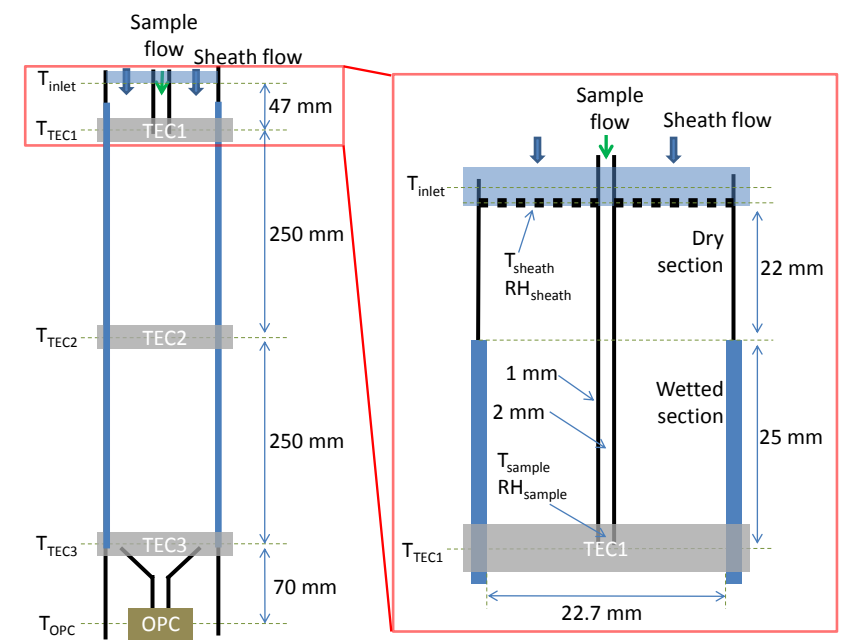

Fig. 1. CCN chamber dimensions and temperatures used in the models.

water vapor) phases are coupled through the release of latent heat and condensation of water vapor.

\subsection{Description of CCN instrument}

A schematic of the CCN chamber is shown in Fig. 1; sheath and aerosol sample flows are introduced into the top of a cylindrical vertical tube. By using a relatively high sheath-toaerosol flow ratio (usually 10:1), the sample flow is focused in a narrow stream at the chamber centerline. Column walls are kept wet and a constant positive wall temperature gradient in the streamwise direction is maintained by three sets of thermo electric coolers (TECs). Because diffusion of water vapor is faster than that of heat, a quasi-parabolic radial supersaturation profile is developed. The streamwise supersaturation profile depends mainly on pressure, flow rate, and wall temperature gradient (Roberts and Nenes, 2005). Flows, temperature, and water vapor concentration need different lengths to develop, but a relatively constant maximum supersaturation is maintained after a characteristic entry length (Lance et al., 2006). At the exit of the chamber, a funnel focuses the sheath and sample flows to a narrow and fast air stream going through the optical particle counter (OPC) view volume. The OPC detects droplets ranging from 0.5 to $10 \mu \mathrm{m}$ diameter.

Different operation modes can be used during instrument calibration and $\mathrm{CCN}$ measurements. Wall temperature gradients can be kept constant, changed with selected steps, or supersaturation can be scanned continuously by adjusting flow rate (Moore and Nenes, 2009). In addition, differential mobility analyzers (DMAs) can be used in selecting dry particle sizes either in stepping or scanning modes (Moore et al., 2010). This study focuses on the constant flow mode of operation, which is currently the most widely-used mode of op- eration for the DMT instrument. A version of the model supporting the scanning flow mode is left for a future study.

\subsection{Droplet growth model}

The rate of change of droplet diameter $D_{p}$ can be described with a differential equation derived from the mass transfer of water vapor to the droplet/particle phase (Fukuta and Walter, 1970; Seinfeld and Pandis, 1998):

$D_{p} \frac{d D_{p}}{d t}=\frac{S-S_{\mathrm{eq}}}{\frac{\rho_{\mathrm{w}} R T}{4 P_{\mathrm{w}}^{0} D_{\mathrm{v}}^{\prime} M_{\mathrm{w}}}+\frac{\Delta H_{\mathrm{v}} \rho_{\mathrm{w}}}{4 k_{\mathrm{a}}^{\prime} T}\left(\frac{\Delta H_{\mathrm{v}} M_{\mathrm{w}}}{T R}-1\right)}$

where $S$ and $S_{\text {eq }}$ are ambient and droplet water equilibrium saturation ratios, respectively. In addition to density of water $\left(\rho_{\mathrm{w}}\right)$, universal gas constant $(R)$, temperature $(T)$, water saturation vapor pressure $\left(P_{\mathrm{w}}^{0}\right)$, molar mass of water $\left(M_{\mathrm{w}}\right)$, and water vaporization enthalpy $\left(\Delta H_{\mathrm{v}}\right)$, the equation contains diffusivity $\left(D_{\mathrm{v}}^{\prime}\right)$ and thermal conductivity $\left(k_{\mathrm{a}}^{\prime}\right)$ terms that account for non-continuum effects (Fukuta and Walter, 1970):

$k_{\mathrm{a}}^{\prime}=\frac{k_{\mathrm{a}}}{1+\frac{2 k_{\mathrm{a}}}{\alpha_{T} D_{p} \rho_{\mathrm{a}} c_{p}} \sqrt{\frac{2 \pi M_{\mathrm{a}}}{R T}}}$

$D_{\mathrm{v}}^{\prime}=\frac{D_{\mathrm{v}}}{1+\frac{2 D_{\mathrm{v}}}{\alpha_{\mathrm{c}} D_{p}} \sqrt{\frac{2 \pi M_{\mathrm{w}}}{R T}}}$

In Eq. (2) $k_{\mathrm{a}}, \rho_{\mathrm{a}}, c_{p}$ and $M_{\mathrm{a}}$ are thermal conductivity, density, heat capacity and average molar mass of air, respectively. $D_{\mathrm{v}}$ is the diffusivity of water in air. Thermal accommodation $\left(\alpha_{T}\right)$ and water vapor uptake $\left(\alpha_{\mathrm{c}}\right)$ coefficients are not well known, but are thought to be close to unity for pure water droplets (e.g. Fukuta and Walter, 1970; Laaksonen et al., 2005; Davidovits et al., 2006; Kolb et al., 2010). In this study, $\alpha_{T}$ is prescribed to be unity, but $\alpha_{\mathrm{c}}$ is determined from the experiments with ammonium sulfate calibration aerosol.

The water equilibrium saturation ratio of the growing droplets is calculated from Köhler theory (Köhler, 1936):

$S_{\mathrm{eq}}=a_{\mathrm{w}} \exp \left(\frac{4 \sigma M_{\mathrm{w}}}{R T \rho_{\mathrm{w}} D_{p}}\right)$

where the Raoult (or "solute") term $\left(a_{\mathrm{w}}=\gamma_{\mathrm{w}} x_{\mathrm{w}}\right)$ gives the change in the water vapor pressure due to the decreased mole fraction of water $\left(x_{\mathrm{w}}\right)$ and solute-water interactions (activity coefficient $\gamma_{\mathrm{w}}$ ). The Kelvin term gives the increase in vapor pressure due to droplet curvature. $\gamma_{\mathrm{w}}, x_{\mathrm{w}}$ and surface tension $(\sigma)$ are known for the calibration aerosol, but not for ambient particles. Therefore, constant surface tension equal to that of pure water $\left(\sigma_{\mathrm{w}}\right)$ is often assumed, which is a good approximation for any dilute droplet, unless it contains strong surfactants. Droplet solution non-idealities are largely ignored (assumed to be independent of solute concentration) when 
$a_{\mathrm{w}}$ is parameterized in terms of a single solute hygroscopicity parameter $\kappa$ (Petters and Kreidenweis, 2007):

$a_{\mathrm{w}}=\left(1+\frac{\kappa}{\left(D_{p} / D_{\mathrm{dry}}\right)^{3}-1}\right)^{-1}$

where $D_{\text {dry }}$ is the dry diameter of the particle.

Equation (1) is an initial value problem, where temperature and both chamber and droplet water equilibrium saturation ratios depend on time or the location in the instrument. The gas-phase model (Roberts and Nenes, 2005; Lance et al., 2006) is used to generate velocity, pressure, supersaturation and temperature fields based on the measured instrument operation parameters (wall temperatures, pressure and flow rates) and calibrated maximum supersaturation.

\subsection{The gas-phase model}

Calculation of gas-phase distributions of pressure, water vapor, temperature and flow velocities is presented in Roberts and Nenes (2005) and evaluated by Lance et al. (2006), Rose et al. (2008), and Lathem and Nenes (2011). The relevant heat and mass transfer equations, the coupling with the droplet phase, and the details about the finite volume integration method are given by Roberts and Nenes (2005) and Lance et al. (2006).

The main uncertainties in the calculation of velocity, pressure, temperature and supersaturation fields are related to boundary conditions of the gas-phase model, especially the temperature and relative humidity of the inlet sample and sheath flows, and the chamber wall temperature and wetting profiles. Flow rates and pressure are quite easily controlled and measured, while temperature control is limited to the outer wall of the chamber, and at the three TEC regions (see Fig. 1).

Inner wall temperatures are not measured, but a comparison between observed and simulated supersaturation dependence on wall temperature gradient indicates that the inner wall temperature gradients are lower than those measured from the outer wall (Lance et al., 2006). In addition, experiments show that supersaturation calibration lines (supersaturation as a function of column top and bottom temperature difference) have a negative offset, i.e. a small temperature gradient is needed for the zero supersaturation (Rose et al., 2008). The model assumption of fully wetted column walls means zero centerline supersaturation for the zero temperature gradient case. Much of these uncertainties related to the supersaturation profiles can be avoided by selecting the inner wall temperature gradient so that the calibrated and calculated maximum supersaturation values match. In the updated model, this is done on-line for any given set of input parameters.

The original gas-phase model of Roberts and Nenes (2005) does not include the chamber section between TEC1 and column top. The impact of this assumption is addressed by developing a new detailed model version that includes the ge- ometry of the complete inlet section. Several assumptions of the inlet region must be made even for the detailed model. First, sheath and sample flow relative humidities are not typically measured. The sample flow is often dried in laboratory measurements, although it can be much higher when sampling in ambient environments without a pre-conditioning dryer. For this work, a sample flow RH of $30 \%$ is assumed. Uncertainty in this parameter has a minor effect on droplet size because the sample flow is usually about $10 \%$ of the total flow. Ideally sheath flow RH is $100 \%$ at the humidifier. Direct measurements of RH indicate that the sheath flow RH depends on the flow rate, being lower for higher flow rates (Sect. 3.2). In practice, sheath flow RH can be an important source of droplet size variability as it affects the entry length required for development of supersaturation in the chamber; the effect on maximum supersaturation however is often negligible. Second, the first few millimeters of the wetted chamber wall could be dryer than expected due to the subsaturated sheath flow. As a result, a smooth wall wetting profile is assumed between the start of the wet wall section and TEC1. Third, sheath flow temperature is known at the column top, but sample flow is in a narrow tube from the column top to the distance of TEC1. Instead of actually solving the heat conduction equations, it is assumed that the tube and the sample flow temperatures are not changing until sheath and sample flows meet at the location of TEC1.

Because temperature boundary conditions are not known after the chamber where the flows are going through the funnel, model simulations end at TEC 3 about $70 \mathrm{~mm}$ before droplets are detected by the OPC. The distance between TEC 3 and OPC is quite small compared to the total chamber length (500 mm from TEC1 to TEC3) and flow velocity increases after the TEC3 when both sample and sheath flows are funneled smoothly into a $1 \mathrm{~mm}$ diameter tube. A simple calculation (assuming linear geometry and that aerosol velocity is equal to the mean velocity) suggest that the time in the funnel is $\sim 0.3 \mathrm{~s}$ for $0.5 \mathrm{~L} \mathrm{~min}^{-1}$ flow rate compared to the $12 \mathrm{~s}$ residence time of the droplets in the chamber.

\section{Results}

The model development is first briefly described before presenting the calibration experiments for model verification. The optical particle counter (OPC) calibration experiments are used to characterize the sizing of the OPC. A series of standard supersaturation calibration experiments are then used to assess if model predictions are in agreement with experimental observations for a water vapor uptake coefficient $\sim 1$. We also assess the impact of various model simplifications on predicted droplet size and compare them to the experimental uncertainties. The last model verification experiment is focused on water vapor depletion effects. Finally, an ambient sample data set is analyzed to demonstrate the applicability of our approach. 


\subsection{Model development}

The original single precision FORTRAN code used in Lathem and Nenes (2011) was first converted to double precision accuracy. This had a considerable impact on reducing model computing time, by increasing the smoothness of the supersaturation fields, and reducing the number of iterations required for convergence. As an example, one simulation was run with a standard quad-core desktop computer using both types of precision for identical inputs (Appendix B); the calculation times for the single and double precision models were $1284 \mathrm{~s}$ and $179 \mathrm{~s}$, respectively. The main reason for the order of magnitude time difference is that the droplet growth calculations are much slower for the single precision model; when the droplet growth is ignored, both model versions need about $50 \mathrm{~s}$ for calculations of the gas-phase fields (pressure, flow velocity, temperature and water vapor concentration). The slower droplet growth calculations of the single precision code is a result of fluctuations to the calculated fields from accumulation of roundoff errors, which slow down the solving of Eq. (1). An example of such fluctuations and their impact on calculated centerline supersaturation profiles is shown in Appendix B.

A further step in the development involved the separation of the gas-phase and droplet growth codes, allowing for more flexible control over these two most time-consuming tasks. Now droplet growth calculations and gas-phase iterations are performed one at a time and only when needed. Some updates were done to model parameters such as the temperature dependence of latent heat of water which had been constant in the previous version. Boundary conditions were also redefined when needed (different model versions specified below). The biggest change from the original code is a new interface between the droplet growth and gas-phase models which allows the on-line calculations of fields from the given maximum supersaturation and instrument operation parameters. Other changes are related to more flexible user inputs and outputs, error handling, and optimization for quick droplet growth calculations.

For the following calculations we are using three model versions of varying complexity. The long model contains the detailed CCN chamber geometry from inlet to TEC3 as shown in Fig. 1. Because the model starts from the flow straightener, uniform initial velocities are assumed for sheath and sample flow regions. Temperature boundary conditions are linear interpolations between the measured temperatures from inlet and TECs, except that the sample tube temperature is set equal to the inlet temperature. Initial water vapor concentrations are calculated from the given sheath and sample flow relative humidities, and these are constants during the dry chamber wall section. After that, chamber wall water vapor concentration increases linearly from the initial value to the saturation concentration at TEC1, and remains saturated after that. Temperature boundary conditions are similar: inlet temperature for the flows, and linear wall temperature pro-

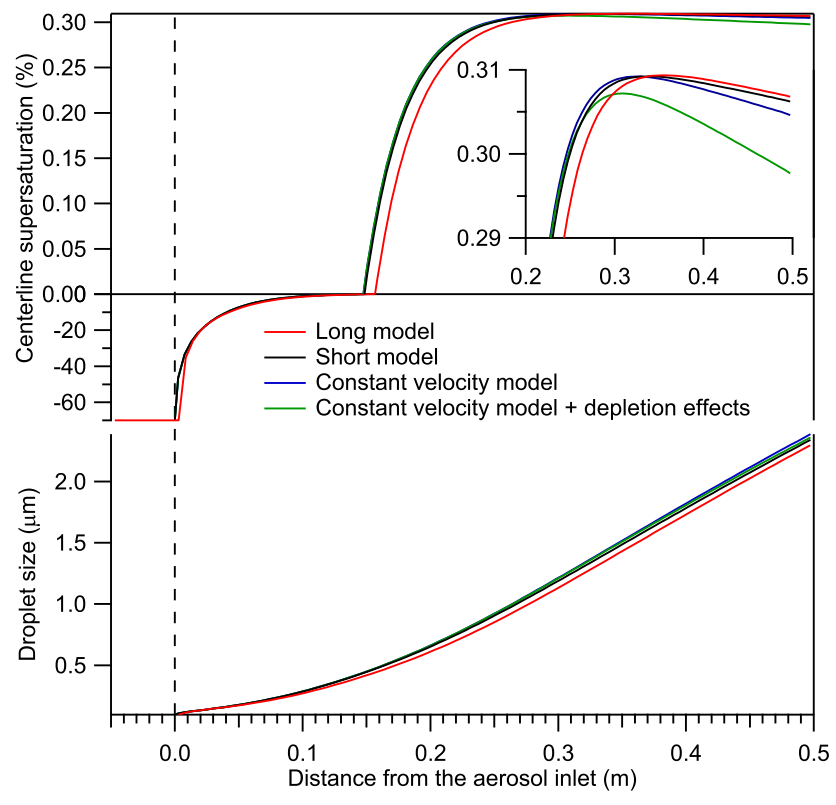

Fig. 2. Simulated centerline supersaturation profiles and droplet size for $90 \mathrm{~nm}$ ammonium sulfate particles. Maximum supersaturation is set to $0.3 \%$ for 1000 mbar pressure and $0.5 \mathrm{~L} \mathrm{~min}^{-1}$ flow rate. Supersaturation in sub- and supersaturated regions are shown in different scales, and the inset shows an expanded view of the region with the highest supersaturation.

files between the inlet, TEC1 and TEC3. The gas-phase part of the short model is identical to that of the original model of Lathem and Nenes (2011), i.e. calculations start from TEC1 with given initial flow temperatures and parabolic axial and zero radial flow velocities. The initial width of the aerosol flow region is calculated from the parabolic flow profile and total volumetric sample flow. Finally, the constant velocity model is similar to the short model except that velocity fields are not calculated. Instead, fully developed flow (assuming constant temperature, pressure and neglecting buoyancy effects) with the initial zero radial velocity and parabolic axial velocity profiles are used for all grid cells. It should be noted that this approximation is not possible for the long model, because the sample flow slows down and expands after the sample inlet tube, which requires explicit calculations of the velocity and pressure fields.

Figure 2 shows an example of calculated centerline supersaturation profiles and droplet sizes from the different model versions. Here maximum supersaturation is set to $0.3 \%$, flow rate is $0.5 \mathrm{~L} \mathrm{~min}^{-1}$, pressure is $1000 \mathrm{mbar}$, sheath-to-aerosol flow ratio (SAR) is 10.0 , TEC1 temperature is $300 \mathrm{~K}$, and inlet temperature is $302 \mathrm{~K}$ for the long model. Particles are $90 \mathrm{~nm}$ in dry diameter and composed of ammonium sulfate $(\kappa=0.6)$. Water vapor depletion effects (particle concentration $600 \mathrm{~cm}^{-3}$ at the instrument pressure and temperature) are accounted for in the second constant velocity model simulation. This is a typical example of how insensitive field and 


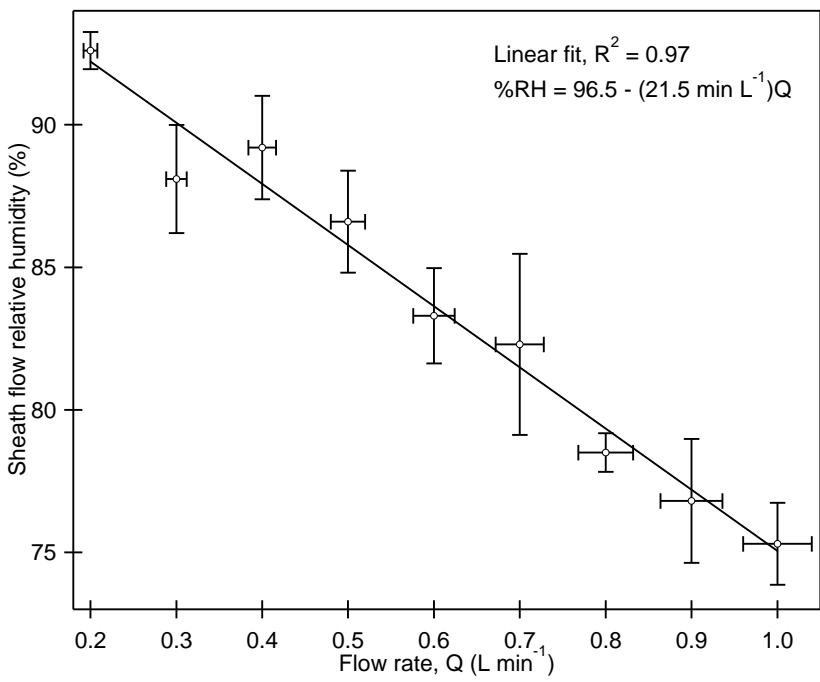

Fig. 3. Example of measured sheath flow relative humidity as a function of flow rate. The $\mathrm{RH}$ error bars represent variability from at least four measurements and the flow rate error bars show the average uncertainty $(4 \%)$.

droplet growth calculations are to most model details, such as the inlet section, when (particle free) maximum supersaturation is fixed. On the other hand, water vapor depletion has an observable effect on the supersaturation profile even for this low particle concentration.

The calculation times for the simulations in Fig. 2 were $1.62 \mathrm{~s}, 239 \mathrm{~s}$, and $362 \mathrm{~s}$ for the constant velocity, short, and long models, respectively. The time for the constant velocity model when accounting for water vapor depletion effects was $2.09 \mathrm{~s}$. If depletion effects become larger, more iterations will be needed and the computing time will increase. For this single particle simulation, computing time depends largely on the time to calculate velocity fields. When constant radial velocity profiles are assumed, total computing time is decreased by about two orders of magnitude.

\subsection{Sheath flow relative humidity}

Sheath flow relative humidity was measured using an $\mathrm{RH}$ meter ( $\pm 3 \% \mathrm{RH}$ accuracy) from the sheath flow line between the Nafion dryer block and the column top of the CFSTGC instrument (serial number CCN007). The CFSTGC liquid flow set was set to "low", sample temperature varied between $21-26^{\circ} \mathrm{C}$, and Nafion temperature varied discretely being either $24.3^{\circ} \mathrm{C}$ or $27.2^{\circ} \mathrm{C}$. The results of the RH measurements are shown in Fig. 3, where the RH error bars represent variability from at least four measurements, and the flow rate error bars show the average uncertainty (4\%). Linear fitting to the data is also shown.

Because sheath flow RH is not commonly measured and it is not known if this calibration curve holds for all instruments used in this study, the model is constrained with a fixed value

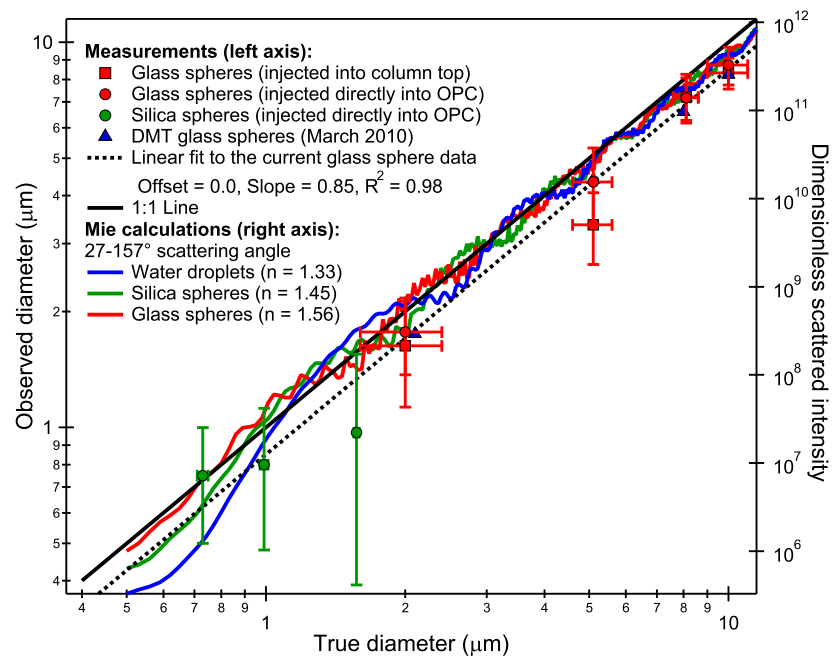

Fig. 4. OPC calibration with glass and silica microspheres (left axis) and the dimensionless scattered intensity from Mie theory for water droplets and size standards (right axis). The observed droplet size values reflect the mean and standard deviation of a Gaussian fit to the OPC distribution. The right axis limits were visually aligned to fall on the one-to-one line.

equal to $80 \%$. Model simulations (not shown here) show that sheath flow RH variations have a negligible influence on the maximum supersaturation, but do affect the supersaturation entry length, and hence, final droplet size.

\subsection{Instrument size calibration}

The optical particle counter (OPC) in the DMT CCN instrument uses a $628 \mathrm{~nm}$ wavelength laser to detect right-angle scattered light (27-153 ${ }^{\circ}$ scattering angle) from droplets entering the beam line. The beam pulses are detected by a photodetector and used to determine the $\mathrm{CCN}$ concentration from 1-s integrated counts, while the scattered light intensity is related to the droplet size. Since the original OPC design work focused mainly on $\mathrm{CCN}$ counting, the accuracy of the sizing over the range of droplet sizes has not yet been thoroughly evaluated.

Here, we use NIST-certified borosilicate glass and silica microspheres from Duke Scientific to verify the OPC sizing. The silica spheres $(0.73 \pm 0.02,0.99 \pm 0.02,1.57 \pm 0.02 \mu \mathrm{m}$ mean diameters) were atomized from an aqueous solution and dried in two silica gel diffusion dryers, while the glass spheres $(2.0 \pm 0.4,5.1 \pm 0.5,8.1 \pm 0.5$ and $10.0 \pm 1.0 \mu$ m mean diameters) were obtained as a dry powder and suspended into the air stream using the DMT glass bead injector. Overall, the atomization technique produced much lower particle concentrations, likely due to wall losses in the long drying section and transport tubing. The dry generation technique worked much better and was used to validate the OPC calibration. Mie theory calculations performed for the instrument geometry using the model of Bohren and Huffman (1983) show 
that the different refractive indices of the silica, glass, and water spheres are not expected to bias the sizing measurement (right axis in Fig. 4).

Two different experimental configurations were used for the OPC calibrations. In the first, the OPC was removed from the base of the column while preserving the electrical and tubing connections. The glass bead injector was placed directly upstream of the OPC and filtered air was drawn through the suspension vial directly into the OPC (tubing length on the order of a few centimeters). This procedure was carried out in August 2011, as well as during routine maintenance at DMT in March, 2010. Removing (and replacing) the OPC from the column is likely to be challenging in the field, and direct injection of the glass particles led to significant broadening due to coincidence errors. Consequently, a second configuration was tested where the glass bead injector was placed in-line with the sample flow between the column top and the low-pressure end of the laminar flow element and a filter was placed on the instrument inlet. In this configuration, the instrument was operated normally with a $0 \mathrm{~K}$ temperature gradient to prevent activation of the glass particles. While being much easier to perform in the field, this second configuration also reduces coincidence errors through mixing the sample and sheath flow as occurs during normal operation of the instrument.

The calibration results shown in Fig. 4 show remarkably good agreement between the measured and standard sizes, but uncover a small undersizing bias $(\sim 15 \%)$, which is important to account for when comparing experimental data with the results of the droplet growth simulations. The bias is the same during both March 2010 and August 2011, suggesting that the OPC sizing is nearly constant despite any environmental variation or changes in the laser characteristics during this time period. While calibration of the OPC with size standards provides confidence in the accuracy and stability of the instrument sizing, this bias (and any others resulting from instrument non-idealities such as non-uniform column wetting) could be determined from comparing model predictions to measurements of ammonium sulfate calibration aerosol.

\subsection{Ammonium sulfate aerosol experiments}

In the next two sections, we present the comparison of model predictions with experimental data obtained for ammonium sulfate aerosol at two different $\mathrm{CCN}$ instrument flow rates $\left(0.5\right.$ and $1.0 \mathrm{~L} \mathrm{~min}^{-1}$ ) and pressures (500 and $960 \mathrm{mbar}$ ) and 7-11 different temperature gradients (temperature difference in the range of $4-26 \mathrm{~K}$ ), which are typical of those used in past field measurements. Aerosol were generated via atomization from an aqueous ammonium sulfate solution before being dryed in two silica gel diffusion dryers and sizeclassified with a differential mobility analyzer. The total particle size distribution and CCN size distributions were obtained using the Scanning Mobility CCN Analysis (SMCA) technique of Moore et al. (2010), and three replicate size scans were made at each set of conditions. A simple scaling analysis (Appendix A) was used to set the operating conditions to obtain similar OPC-measured droplet sizes.

A sigmoidal function was fit to the $\mathrm{CCN}$ activation curves obtained from SMCA, and the particle size at the inflection point of the sigmoid was used with Köhler theory to calibrate the instrument maximum supersaturation, following Moore et al. (2010) and Rose et al. (2008). The mean column temperature was used in applying Köhler theory and solution non-ideality was accounted for using an osmotic coefficient obtained from the ion-interaction approach of Pitzer and Mayorga (1973) with parameters taken from Clegg and Brimblecombe (1988).

The main variables for the four calibration experiments with different pressures and flow rates are dry particle size and supersaturation. To simplify the comparison with model predictions, we have interpolated average droplet size for $90 \mathrm{~nm}$ dry particle size using the data from $80-100 \mathrm{~nm}$ dry size range, which is common for all mobility scans. Linear interpolation was used because droplet size depends on dry particle size (larger dry size leads to larger droplets) and single data points can be affected by noise and/or fluctuations. Pressures, flow rates, sheath-to-aerosol flow ratios and column top temperatures do not depend on dry particle size, so these were averaged for the four calibration experiments. The resulting values, which are given in Table 1, are used as model input parameters.

\subsection{Optimal water vapor uptake coefficient for calibration aerosol}

A wide range of water vapor uptake coefficient $\left(\alpha_{c}\right)$ values have been reported in the literature, so here we use our calibration experiments to constrain $\alpha_{\mathfrak{c}}$, which is expected to range from 0.1 to 1.0 . Because the three model versions (Sect. 3.1) predict very similar droplet sizes, only the constant velocity model is used here. The model includes the effect of water vapor depletion.

Figure 5 shows observed droplet sizes from the four calibration experiments and corresponding predictions from the constant velocity model using different water vapor uptake coefficients. Predictions and observations match within experimental uncertainty when the uptake coefficient is larger than 0.05 , but unity $\alpha_{\mathrm{c}}$ seems to be more likely for the two 963 mbar experiments. In calculations hereafter, we assume $\alpha_{\mathrm{c}}=0.2$ given that it lies within the range of acceptable values, and is in agreement with measurements carried out for droplet water isotopic exchange experiments (Li et al., 2001).

It should be emphasized that observed droplet size was corrected by using the OPC calibration equation in Fig. 4. Without this correction, a significantly lower $\alpha_{\mathrm{c}}$ would have been needed to match model predicted droplet sizes with the observations. However, as shown in Lathem and Nenes 
Table 1. Average flow rate $(Q)$, pressure $(P)$, sheath-to-aerosol flow ratio (SAR), TEC1 and inlet temperatures, and CCN concentrations at the instrument pressure and temperature for the four calibration experiments.

\begin{tabular}{cccccc}
\hline$Q\left(\mathrm{~L} \mathrm{~min}^{-1}\right)$ & $P(\mathrm{mbar})$ & $\mathrm{SAR}$ & $T_{\mathrm{TEC} 1}(\mathrm{~K})$ & $T_{\text {inlet }}(\mathrm{K})$ & $\mathrm{CCN}\left(\mathrm{cm}^{-3}\right)$ \\
\hline 0.50 & 501.0 & 10.00 & 299.0 & 301.2 & 598 \\
0.50 & 963.0 & 10.04 & 299.5 & 301.7 & 320 \\
1.00 & 500.0 & 10.04 & 299.2 & 301.4 & 618 \\
1.00 & 963.0 & 9.96 & 299.8 & 302.0 & 151 \\
\hline
\end{tabular}
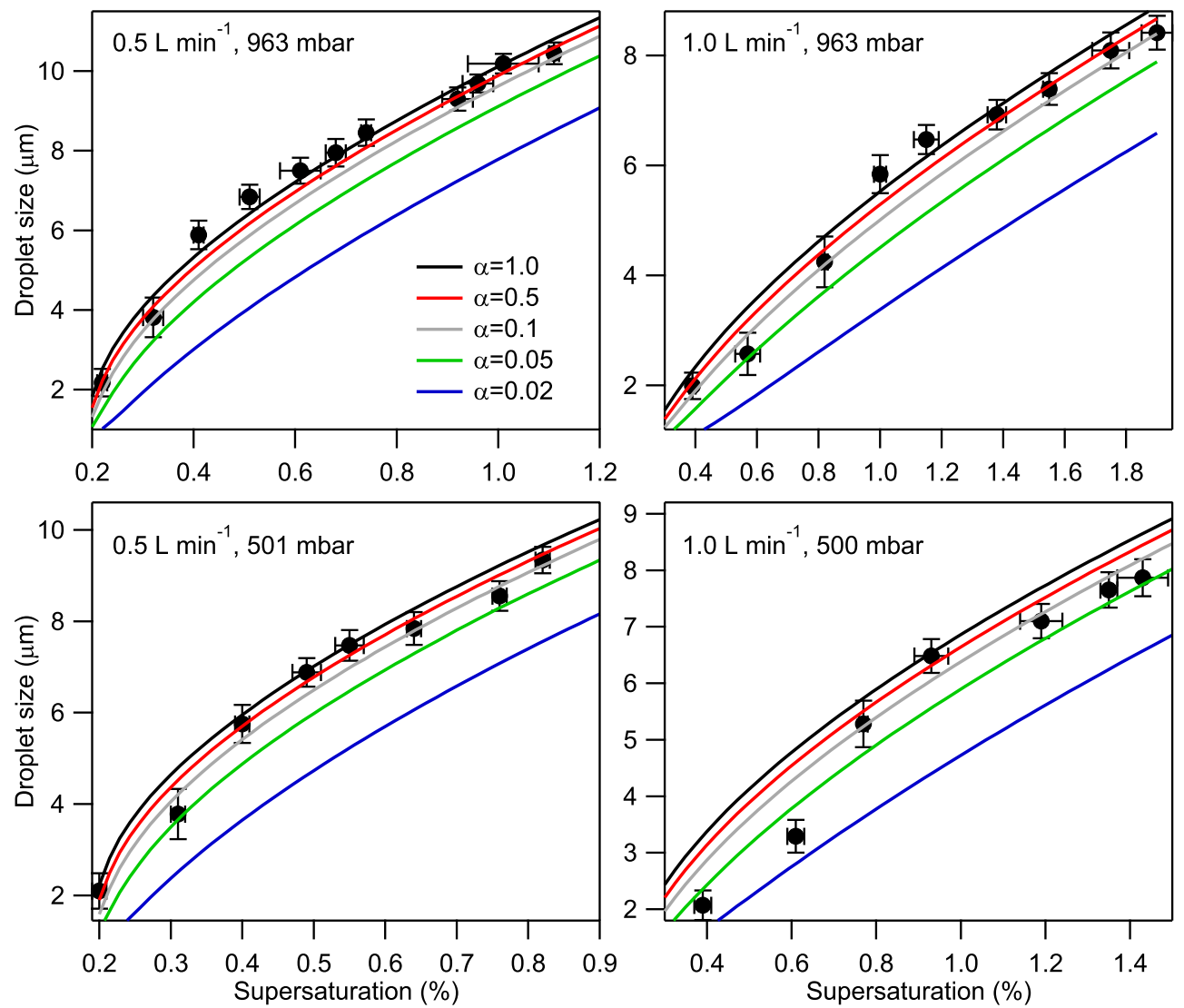

Fig. 5. Observed and predicted droplet size for $90 \mathrm{~nm}$ ammonium sulfate particles. Model predictions are from the constant velocity model when using different water vapor uptake coefficients. Supersaturation error bars are based on uncertainties of the calibrated supersaturations and droplet size error bars are the average distribution widths described by standard deviations.

(2011) and in Sect. 3.7, high $\alpha_{\mathrm{c}}$ values are needed to correctly predict water vapor depletion effects.

\subsection{Different model versions}

When the correlation between observed and predicted droplet sizes agree within experimental uncertainty (Fig. 5), little or no improvement can be achieved by changing model geometry, calculating velocity fields or further optimizing uncertain model parameters such as the sheath flow RH. Figure 6 shows the measured droplet sizes of activated $90 \mathrm{~nm}$ ammonium sulfate particles and predictions based on the long, short and constant velocity models. In addition to the default sheath flow RH of $80 \%$, a much lower value of $50 \%$ was used in the second constant velocity model simulation. This has some effect on the $1.0 \mathrm{~L} \mathrm{~min}^{-1}$ and 963 mbar case, but generally the change in droplet size is small. Water vapor depletion effects are accounted for only in the third constant velocity model simulation. Large differences are not expected for these low CCN concentration experiments, but a clear difference is seen for all except the $1.0 \mathrm{~L} \mathrm{~min}^{-1}$ and 963 mbar case. Higher CCN concentrations are examined in the next section.

Droplet sizes predicted by the constant velocity model are always slightly larger than those from the models with calculated velocity fields, because calculated velocity fields in the 

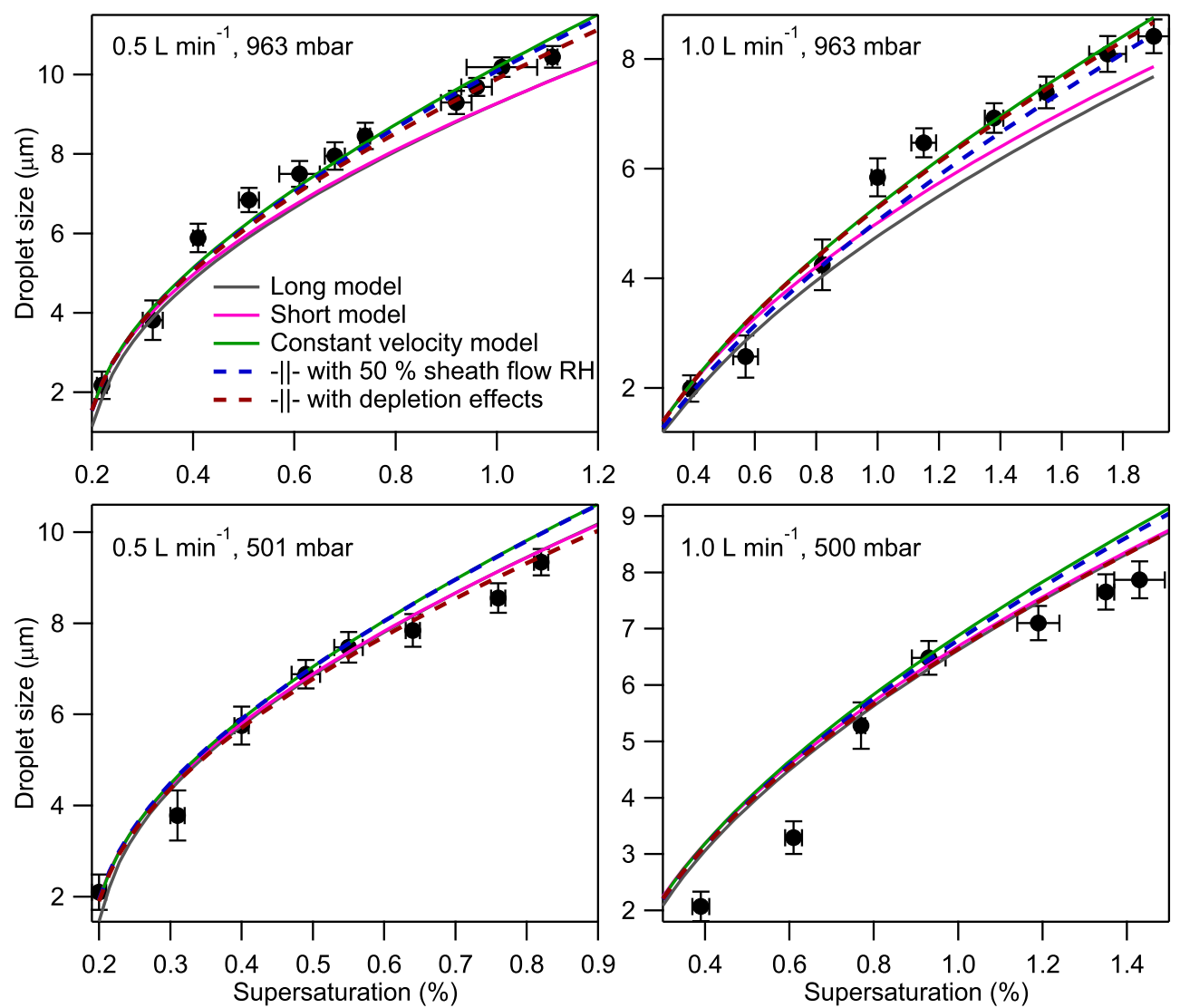

Fig. 6. Observed and predicted droplet size for $90 \mathrm{~nm}$ ammonium sulfate particles. Constant water uptake coefficient of 0.2 is assumed for all model versions. The experimental data is same as in Fig. 5.

latter have higher centerline velocities and thus less time for growth. The main reason is that the calculated velocity profiles are affected slightly by buoyancy and thermal expansion in the streamwise direction (not shown). Despite these differences, the change in droplet size predicted by the models with and without velocity calculations is small enough that velocity calculations can be ignored, reducing computational time by about two orders of magnitude.

Figure 6 also shows that the detailed description of the inlet section before TEC1 does not change model predictions noticeably. The reason is that droplet size is not changing much during the sub-saturated section of the chamber, and when RH exceeds $100 \%$ for the first time, flow fields are already similar for all model versions. Figure 7 shows an example of supersaturation fields (contour lines) calculated by the long model. Negative values of the axial coordinate represent the inlet region, where sample and sheath flows are separated. The dashed black lines are streamlines for the sample flow region. These start from the point where sheath and sample flows meet, i.e. right after the sample inlet shown by the black boxes. For these simulations, maximum aerosol section supersaturation was $0.3 \%$, pressure 500 or $1000 \mathrm{mbar}$, flow rate 0.5 or $1.0 \mathrm{~L} \mathrm{~min}^{-1}$, and inlet and TEC 1 temperatures 302 and
$300 \mathrm{~K}$, respectively. Flows have developed when the streamlines become parallel with the chamber symmetry axis, and this happens well before $100 \% \mathrm{RH}$ is reached.

\subsection{Water vapor depletion}

As shown by Lathem and Nenes (2011), growing droplets can significantly deplete water vapor in the instrument chamber when CCN concentration is large enough. This leads to decreased centerline supersaturation and droplet size. Lathem and Nenes (2011) showed that the model is able to correctly predict the droplet size decrease for ammonium sulfate when using a water vapor uptake coefficient close to unity. These experiments were performed at ambient pressure and $0.5 \mathrm{~L} \mathrm{~min}^{-1}$ flow rate; the model should also correctly predict droplet size depression for any pressure and flow rate as long as droplet size and CCN concentration are correctly predicted. Model accuracy for predicting droplet size was shown above; $\mathrm{CCN}$ concentrations are even easier to predict, because they depend largely on the equilibrium critical dry particle size. We have, nevertheless, carried out additional high $\mathrm{CCN}$ concentration calibration experiments at reduced pressure to study the effect of pressure on water vapor depletion. 

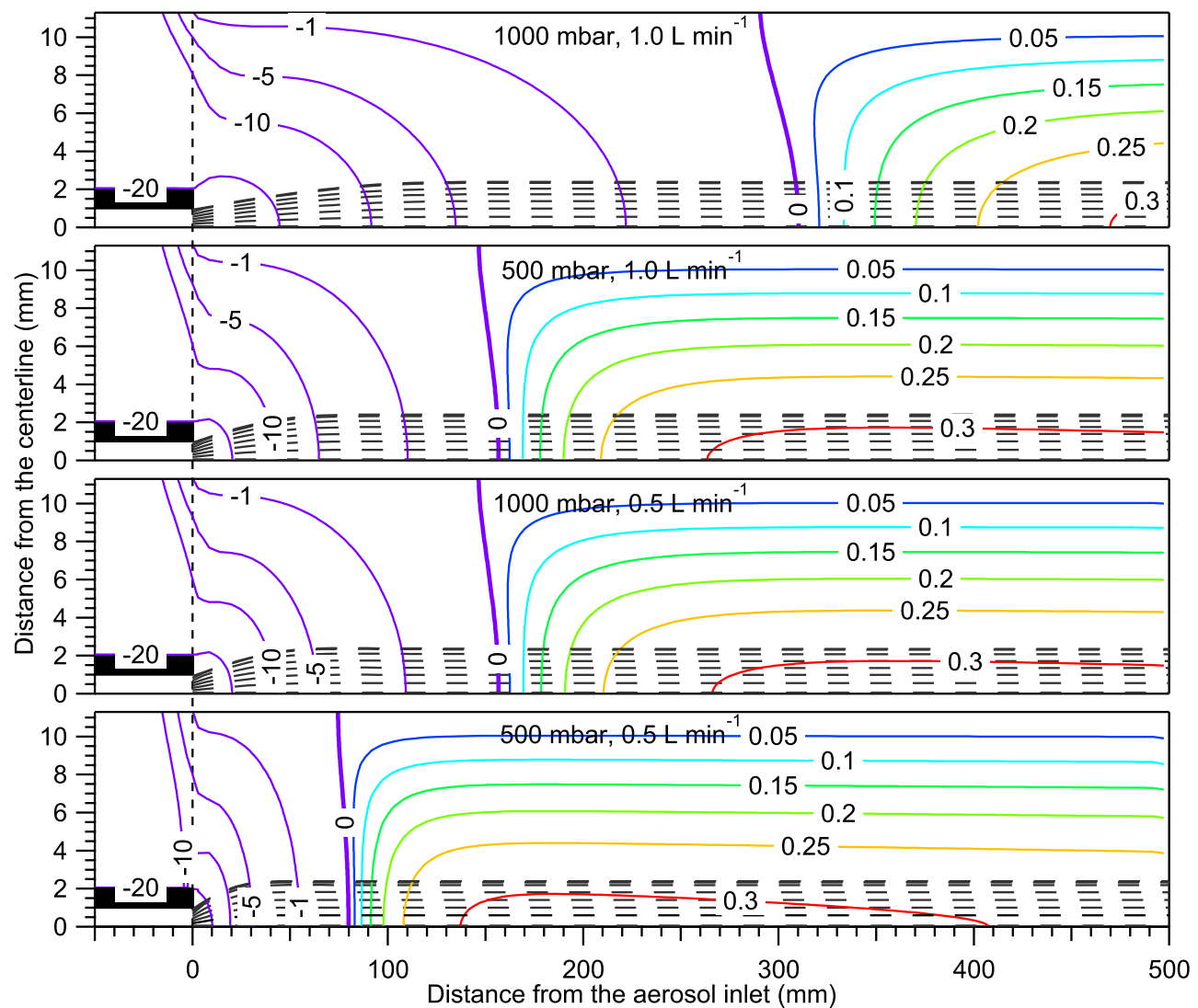

Fig. 7. Calculated supersaturation fields from the long model (colored contour lines and labels in \%) and trajectories for aerosol sections (dashed black lines).

Figure 8 shows the relative droplet size depressions (droplet size divided by that at the lowest CCN concentration) from four high $\mathrm{CCN}$ concentration calibration experiments. In addition to the 980 mbar data from Lathem and Nenes (2011), there are three additional experiments shown for 450 mbar pressure and a total column flow rate of $0.5 \mathrm{~L} \mathrm{~min}^{-1}$. The experimental procedures for these three additional experiments are about identical to those from Lathem and Nenes (2011), with the addition of a DMT pressure control box upstream of the CCN instrument to control and lower the $\mathrm{CCN}$ pressure. First, a wide polydisperse aerosol size distribution is generated by atomizing an ammonium sulfate solution and drying the droplets with a series of diffusion dryers. After the dryers, one part of the flow is led to a DMA and CPC to measure the dry particle size distribution, and the other polydisperse part is led to the $\mathrm{CCN}$ instrument. $\mathrm{CCN}$ concentrations were varied between 70 and $60000 \mathrm{~cm}^{-3}$ by either changing the concentration of the atomizer solution or adjusting a particle-free dilution flow (while ensuring the mean diameter of the distribution was relatively constant). The dry particle size distributions resemble skewed log-normal distributions containing more particles at the larger sizes.
As shown in Fig. 8, the most important parameter for water vapor depletion is $\mathrm{CCN}$ concentration. From the experimental data, it is difficult to see any clear effect of dry particle size or pressure on water vapor depletion. The water vapor depletion seems to depend on supersaturation, such that at higher supersaturations the water vapor depletion effects are the strongest. This is what can be expected, as droplet size increases with supersaturation. At very low supersaturations, the average droplet size is near the detection limit of the optical particle counter (about $1 \mu \mathrm{m}$ diameter), so droplet size depression is subject to this measurement uncertainty. For Fig. 8, we have removed this data where the initial droplet sizes were close to the instrument detection limit. Therefore, the data represents maximum water vapor depletion effects (for the current supersaturation limits, pressures and dry size distributions).

Noting the experimental uncertainties, we have performed a simplified series of constant velocity model simulations representing the maximum water vapor depletion case: 980 mbar pressure, constant $60 \mathrm{~nm}$ dry size (which may be a bit low for activated particles), and $0.6 \%$ supersaturation. The main variable, however, is the water vapor uptake coefficient. The model simulations shown in Fig. 8 suggest that the largest $\alpha_{\mathrm{c}}$ are needed to adequately account for water vapor 


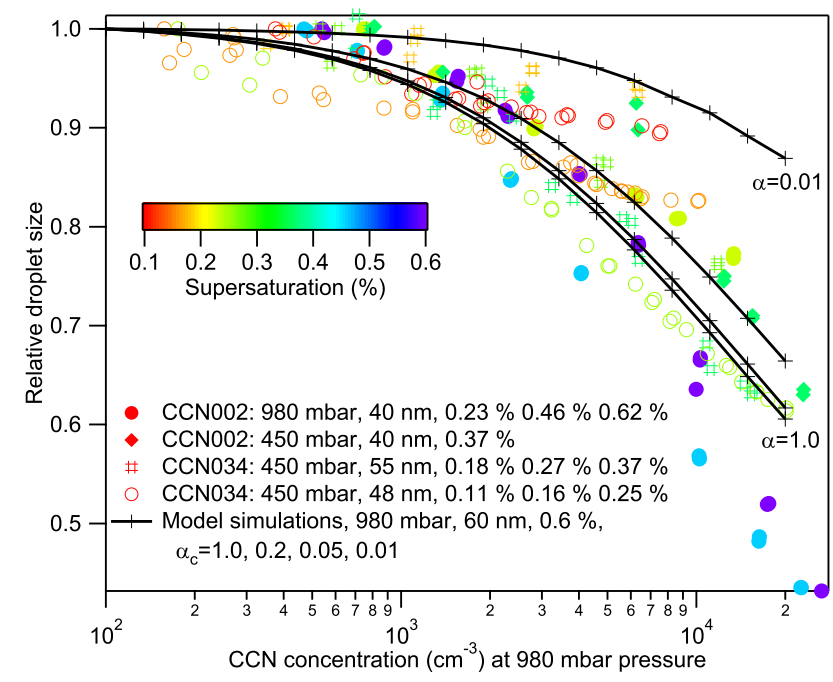

Fig. 8. Relative droplet size (normalized by that of the lowest $\mathrm{CCN}$ concentration) as a function of $\mathrm{CCN}$ concentration from four experiments and constant velocity model simulations. Experimental and simulation details (instrument serial number, pressure, geometric mean dry diameter for experiments and dry particle size for simulations, supersaturations, and water uptake coefficient for simulations) are given in the figure. The experimental results are colored by supersaturation. Both the experiments and simulations represent cases with relatively large vapor depletion effect. The 980 mbar experimental data is from Lathem and Nenes (2011).

depletion effects. For the highest $\mathrm{CCN}$ concentrations, the model seems to under predict water vapor depletion effects even with the highest $\alpha_{\mathrm{c}}$. It is however likely that the highest observed $\mathrm{CCN}$ concentrations are underestimated due to coincidence events in the OPC. Indeed, the model simulations with $\alpha_{\mathrm{c}}=0.2$ shows a good correlation with the experimental data for CCN concentrations at least up to $10000 \mathrm{~cm}^{-3}$ (where coincidence errors are not expected to be important). This can be considered as another strong piece of evidence for a high water uptake coefficient $(\geq 0.1)$.

\section{Application of the model to sample ARCTAS data set}

This section presents an example application of the new method to analyze ambient data obtained during the ARCTAS (Arctic Research of the Composition of the Troposphere from Aircraft and Satellites) campaign. ARCTAS took place in Alaska and western Canada during spring and summer 2008 , respectively, with a main objective to study the effects of aerosol and gas phase pollution on Arctic climate (Jacob et al., 2010). Here we show results from flight 18 from 1 July 2008; the detailed analysis of the ARCTAS campaign data is left to another study (Lathem et al., 2012). Flight 18 was a detailed study of the Lake McKay fire in NW Saskatchewan, Canada, including multiple plume transects to study conditions near the source, as well as transects downwind to study atmospheric plume aging. As a result, the sampled aerosol varies between fresh smoke, aged biomass burning and remote boreal forest background. Not surprisingly, aerosol size, composition, and number concentration were highly variable. Therefore, this data set is an ideal test for the model, especially since the observed CCN concentrations were high enough to lead to significant water vapor depletion in the instrument.

A NASA DC-8 research aircraft was equipped with a DMT CCN counter, which was operated at 451 mbar pressure, $0.5 \mathrm{~L} \mathrm{~min}^{-1}$ total flow rate, 11.3 sheath-to-aerosol flow ratio, and $305 \mathrm{~K}$ column top temperature (average values given). Instrument supersaturation was stepped between three calibrated supersaturations: $\sim 0.28,0.42$, and $0.57 \%$. Ambient aerosol was sampled using the Langley Aerosol Research Group Experiment (LARGE) aircraft inlet, which has 3-4 $\mu \mathrm{m}$ cut size (McNaughton et al., 2007). Dry particle size distributions $(8.5-414 \mathrm{~nm})$, which are needed for the model simulations, were measured by a Scanning Mobility Particle Sizer (SMPS). Time resolution for the DMT CCN counter is $1 \mathrm{~s}$, but measuring the full dry particle size distribution with the SMPS required $105 \mathrm{~s}$, so the $\mathrm{CCN}$ measurements were averaged over this time period. Dry particle hygroscopicity, which is also needed for the model, is inferred from measurements of $\mathrm{CCN}$ activity and aerosol size distribution. When all particles are internally mixed or have the same hygroscopicity, particles larger than a certain critical dry diameter $\left(D_{\mathrm{c}}\right)$ are activated at each given CCN counter supersaturation. This critical dry diameter is calculated from the dry particle size distributions and measured $\mathrm{CCN}$ concentrations, and is converted to hygroscopicity described by the $\kappa$ parameter (Petters and Kreidenweis, 2007):

$\kappa=\frac{4\left(\frac{4 \sigma_{\mathrm{w}} M_{\mathrm{w}}}{R T \rho_{\mathrm{w}}}\right)^{3}}{27 D_{c}^{3} \ln ^{2}(S)}$

Here $S$ is the instrument saturation ratio and the other parameters are same as those in Eq. (4). Time series of the timedependent model input parameters as well as the measured droplet size spectrum are shown in Fig. 9.

The correlation between observed and model-predicted average droplet sizes are shown in Fig. 10. The predictions are calculated using the constant velocity model with and without water vapor depletion effects. At first it seems that the observed droplet growth is significantly delayed, because the model predicts $2-3 \mu \mathrm{m}$ larger droplet size. For example, the observed droplet size for $0.57 \%$ supersaturation is about $5 \mu \mathrm{m}$ when the model predicts about $8 \mu \mathrm{m}$ droplet size. OPC sizing bias could explain a fraction of the difference, but a $\sim 40 \%$ undersizing, which would be required to match the droplet sizes, is unlikely. Another explanation is that droplets really are smaller either due to slower water vapor uptake (kinetic limitations) or factors not accounted for by the model such as unexpected changes in sheath and sample flow RH, droplet evaporation between TEC3 and OPC, 


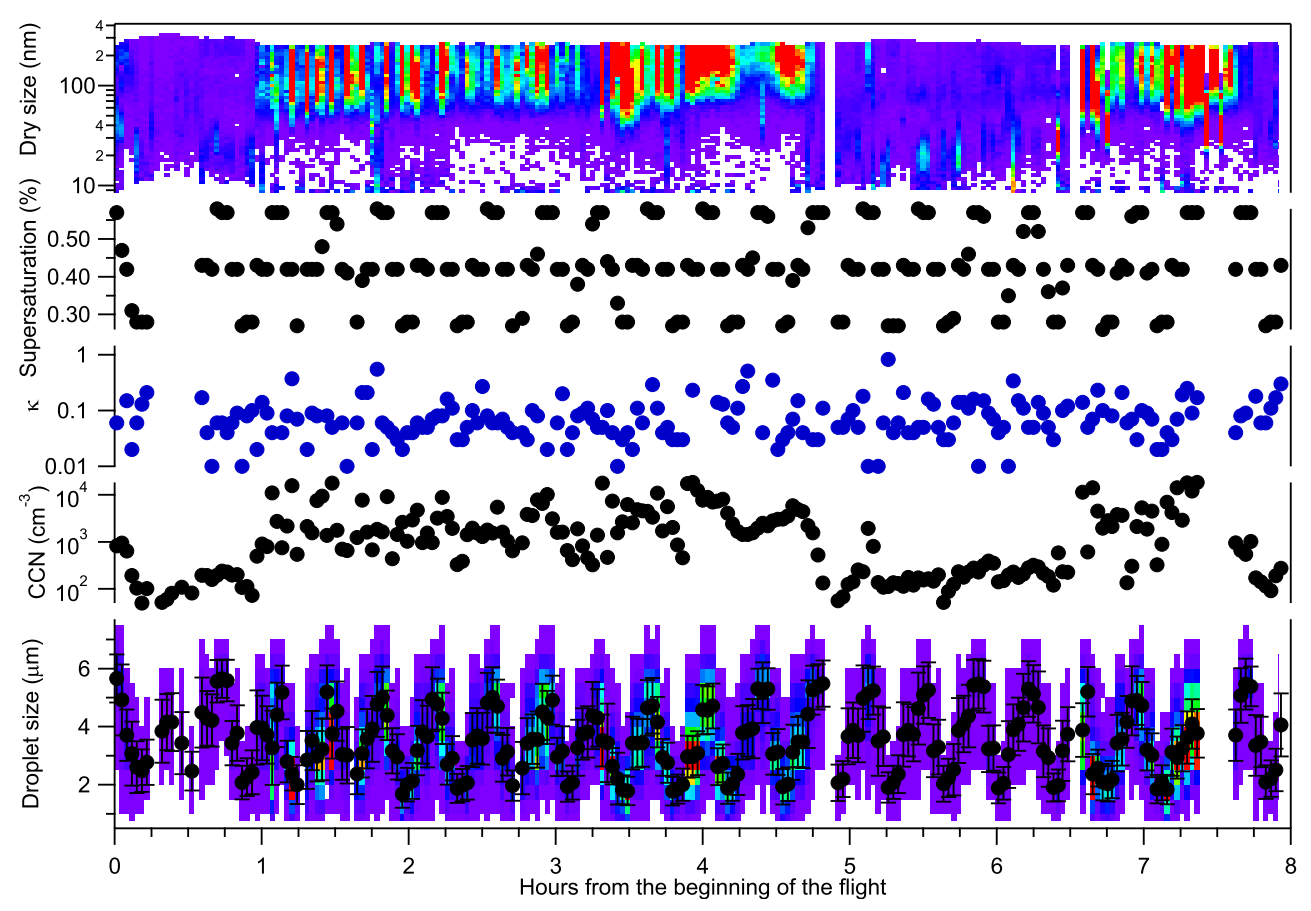

Fig. 9. Droplet size distribution at the instrument exit, $\mathrm{CCN}$ concentration (standard temperature and pressure), hygroscopicity parameter $\kappa$ (largest values are not shown), calibrated supersaturation and dry particle size distribution (standard temperature and pressure) for the ARCTAS flight 18. Average droplet size and standard deviation (error bars) are shown with the droplet size distribution. The color scales of the dry particle and droplet size distributions range from 1 to $10000 \mathrm{~cm}^{-3}$ and 1 to 1000 counts s$^{-1}$, respectively.

incomplete column wetting, and non-linear wall temperature profiles. Calibration data, where kinetic limitations can be excluded, can provide further information about the explanation. Model simulations for the ARCTAS calibration data (black square markers in Fig. 10) showed that the difference between observed and predicted droplet sizes is similar to that of the flight data, which means that slow activation kinetics do not cause the small observed droplet size. In general, it seems that there are differences between the instruments which is seen as differences in the observed droplet size when the nominal operation parameters (supersaturation, pressure and flow rate) and dry particle properties are identical. These differences seem to be practically constant over long (months-years) time periods. Therefore, the model is best suited in explaining changes in droplet size rather than absolute values.

There are clear variations in the observed droplet size, which are represented by the widths of the gray boxes in Fig. 10. Variations in dry particle properties (hygroscopicity and dry particle size distributions) and instrument settings (supersaturation, which is not entirely constant) have a relatively small effect on predicted droplet size; this is seen as practically constant model predictions for each fixed instrument supersaturation (the lower plot in Fig. 10). When water vapor depletion is accounted for, the correlation between observed and predicted droplet sizes becomes clear (the upper plot in Fig. 10). The solid black line is a linear fit with Pear- son correlation coefficient $0.95\left(R^{2}=0.90\right)$, and the offset and slope are $2.0 \mu \mathrm{m}$ and 1.19 , respectively. The conclusion from the correlation is that water vapor depletion can explain the majority of changes in the average droplet size. Without the model and the knowledge about water vapor depletion effects, these changes could have been incorrectly interpreted as a change in water vapor uptake coefficient.

There are still some variations in the observed droplet size that cannot be explained by the model. Fluctuations in the instrument operation parameters may cause real droplet size variations, but it is more likely that the model cannot predict these due to the highly simplified description of hygroscopicity and averaged dry particle size distributions. For example, the assumption of internally mixed particles with uniform hygroscopicity distribution is the simplest approach, but may not be the most accurate, because several different and mixed air mass types were sampled during flight 18 . In this case, model accuracy depends on the practical limitations in probing dry particle properties.

\section{Conclusions}

We present a novel and comprehensive approach to study CCN activation kinetics by coupling a detailed model of the process with $\mathrm{CCN}$ measurements. Thus, we have updated the fully coupled DMT CCN counter gas-phase and droplet 


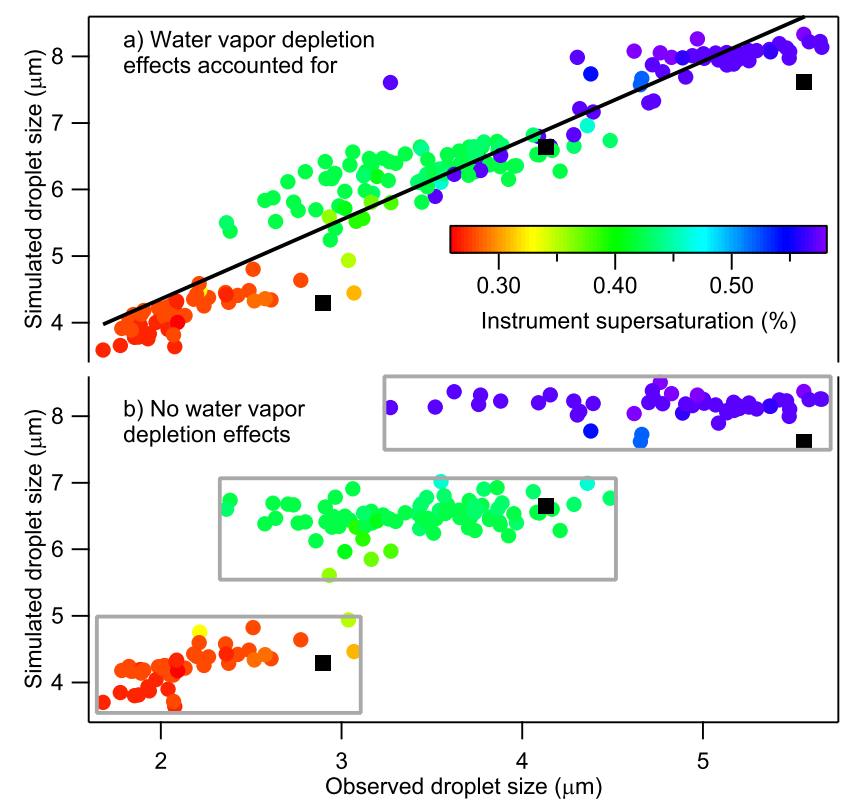

Fig. 10. Simulated droplet size as a function of observed droplet size. Simulations in the upper plot account for water vapor depletion effects, but these are ignored in the simulations shown in the lower plot. The marker color is based on instrument supersaturation. The black square markers represent average data from the calibration experiments and simulations. The gray boxes show the approximate extent of observed and predicted (without water vapor depletion) droplet size variability for the three common supersaturations.

growth model, which simulates droplet growth in the instrument while fully accounting for water vapor depletion effects (Lathem and Nenes, 2011), changes in the instrument operation parameters, and dry particle properties (hygroscopicity and dry size distributions). The updated model is more reliable and faster by an order of magnitude. By assuming constant velocities, it can be further accelerated by an additional two orders of magnitude without significant loss of accuracy, making it suitable for examining large data sets. Model accuracy was verified by a detailed comparison with ammonium sulfate calibration data covering a wide range of instrument operation parameters, including high CCN concentrations. The optical particle counter (OPC) was carefully calibrated using different particle standards. When the observed $15 \%$ undersizing was accounted for and water vapor uptake coefficient was set to 0.2 , model predicted and observed droplet sizes were in excellent agreement. This uptake coefficient is also large enough so that water vapor depletion effects are correctly accounted for up to large CCN concentrations. Exceedingly high CCN concentrations should be avoided, because droplet detection may be subject to considerable coincidence errors and supersaturation depression.

Three model versions were presented above, but the simplest and fastest constant velocity model is recommended for general use. The model and a brief user manual are available from http://nenes.eas.gatech.edu/Experiments/ CFSTGC.html. To be able to use the model for droplet growth simulations, dry particle size distributions and hygroscopicity needs to be known, but the instrument operation parameters (e.g. temperatures, flow rates and pressure) are always saved and the supersaturation is from the usual calibration experiments. Careful OPC calibration and possibly also tuning of model parameters (e.g. measuring and using accurate sheath flow $\mathrm{RH}$ ) are needed to obtain numerical values for the water vapor uptake coefficient. The simplest use of the model, which does not require any additional calibrations or model tuning, is predicting relative changes in droplet size from the effects not related to water vapor uptake (changes in instrument operation parameters, water vapor depletion and changes in dry particle properties). This method was used in the first two applications, one shown here and the other in Moore et al. (2012), of the updated model on real ambient $\mathrm{CCN}$ measurements. In both cases, the model has shown the importance of water vapor depletion effects on droplet size. If unaccounted for, the effect of water vapor depletion could have been interpreted as a change in the water vapor uptake coefficient.

Most of the past DMT CCN studies have focused on CCN concentrations and have largely ignored the capability of the instrument to detect droplet size. As a result, there is a large amount of unanalyzed droplet size data including chamber experiments and field measurements from all over the world. The approach outlined here allows the extraction of $\mathrm{CCN}$ activation kinetics from this data and will allow the development a much-needed climatology of $\mathrm{CCN}$ activation kinetics.

\section{Appendix A}

\section{Droplet growth scaling analysis}

Starting with a simplified form of the Maxwellian condensational growth equation (Eq. 1)

$D_{p} \frac{d D_{p}}{d t}=G\left(s-s_{\mathrm{eq}}\right)$

where $s$ and $s_{\mathrm{eq}}$ are the chamber and droplet water equilibrium supersaturations, respectively, and the parameter $G=$ $\frac{1}{\frac{\rho_{\mathrm{W}} R T}{4 P_{\mathrm{W}}^{0} D_{\mathrm{V}}^{\prime} M_{\mathrm{W}}}+\frac{\Delta H_{\mathrm{V}} \rho_{\mathrm{W}}}{4 k_{\mathrm{a}}^{\prime} T}\left(\frac{\Delta H_{\mathrm{v}} M_{\mathrm{W}}}{T R}-1\right)}$, which is only weakly dependent on particle size and the instrument operating conditions. If critical supersaturation $s_{c} \ll s$ after the instrument supersaturation develops (typical of large hygroscopic particles), one can assume that $s-s_{\mathrm{eq}} \approx s$ (Nenes et al., 2001). Then from applying the chain rule to Eq. (A1) using the droplet velocity (assumed to be equal to twice the mean flow velocity, $U=d x / d t=Q / \pi R^{2}$ ) yields the droplet growth rate along the Eulerian distance in the instrument growth chamber:

$D_{p} \frac{d D_{p}}{d x}=\frac{\pi R^{2}}{2 Q} G s$ 


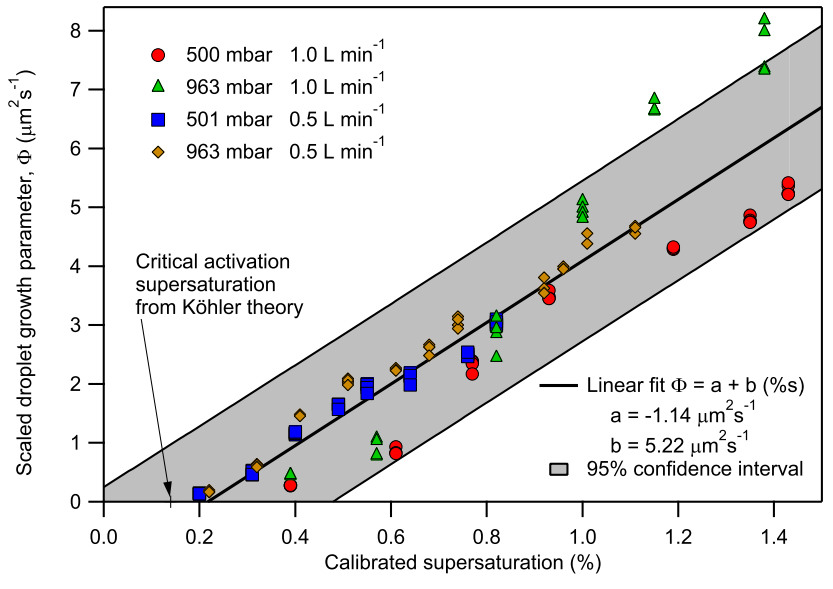

Fig. A1. Dimensionless scaling of droplet size $(\Phi)$ versus calibrated instrument supersaturation for measured $100 \mathrm{~nm}$ ammonium sulfate particles.

where $x$ is the axial distance along the growth chamber, $R$ is its inner radius, $Q$ is the total flow rate, and $s$ is supersaturation. Since the particles effectively activate immediately upon entering the fully-developed supersaturation region of the instrument, Eq. (A2) can be integrated from the point of activation to the outlet of the growth chamber to yield the OPC-measured droplet size, $D_{p}$, OPC

$D_{p, \mathrm{OPC}}^{2}-D_{p, c}^{2}=\frac{\pi R^{2} G s}{Q}\left(L-x_{s}\right)$

where $D_{p, c}$ is the wet droplet diameter at activation described by Köhler theory, $L$ is the total length of the growth chamber, and $x_{\mathrm{s}}$ is the supersaturation entry length given by Lance et al. (2006) as $0.20 R e_{R} R+R^{2} U / \alpha$. $R e_{R}$ is the dimensionless Reynolds number and $\alpha$ is the thermal diffusivity of air. Substituting for $x_{s}$ in Eq. (A3) yields

$D_{p, \mathrm{OPC}}^{2}-D_{p, c}^{2}=R^{2}\left(\frac{\pi L}{Q}-\frac{0.20}{v}-\frac{1}{\alpha}\right) G s$

where $v$ is the kinematic viscosity of air. Then, by rearranging Eq. (A4), we define the droplet growth parameter, $\Phi$, as

$\Phi=\frac{D_{p, \mathrm{OPC}}^{2}-D_{p, c}^{2}}{R^{2}\left(\frac{\pi L}{Q}-\frac{0.20}{v}-\frac{1}{\alpha}\right)}=G s$

Equation (A5) shows that $\Phi$ is expected to scale linearly with supersaturation independent of the instrument operating parameters (assuming a constant value of $G$ ). This is confirmed by the ammonium sulfate calibration data obtained at two different pressures and flow rates shown in Fig. A1. Both $v$ and $\alpha$ are pressure-dependent, and values for air obtained from Seinfeld and Pandis (1998) were used in computing $\Phi$ for Fig. A1.

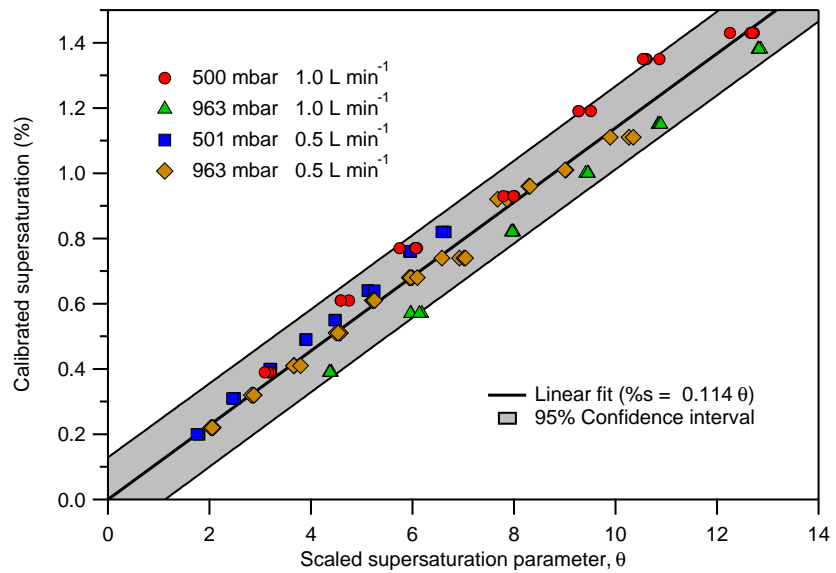

Fig. A2. Calibrated supersaturation versus scaled supersaturation parameter $(\theta)$ for measured $100 \mathrm{~nm}$ ammonium sulfate particles.

The maximum supersaturation in the instrument depends on the pressure, flow rate, applied streamwise temperature gradient $\left(\frac{\Delta T}{L}\right)$, and to a lesser extent, the TEC1 temperature $\left(T_{\mathrm{TEC} 1}\right)$. Consequently, we can parameterize the supersaturation in terms of these parameters as

$s=\beta \theta$

where

$\theta=\left(\frac{300 \mathrm{~K}}{T_{\mathrm{TEC} 1}}\right)^{4}\left(\frac{P}{1000 \mathrm{mbar}}\right)\left(\frac{Q}{1 \mathrm{Lmin}^{-1}}\right)\left(\frac{\Delta T}{1 \mathrm{~K}}\right)$

and the fitting parameter, $\beta$, obtained from the ammonium sulfate calibration data (Fig. A2) is found to be $0.114 \%$. This value does not account for thermal efficiency variations (Lance et al., 2006) or $\Delta T$ offset (Rose et al., 2008), but still is in excellent agreement with the value of $0.144 \%$ obtained for 810 model simulations over a range of $0.5,0.75$, and $1.0 \mathrm{~L} \mathrm{~min}^{-1}$ flow rates, 500, 750, and 1000 mbar pressures, fifteen column temperature differences (from 1 to $15 \mathrm{~K}$ ), and six TEC1 temperatures (from 300 to $310 \mathrm{~K}$ ). While not as rigorous as the parameterization of Lance et al. (2006) as evidenced by the wide confidence region $( \pm 0.1 \%$ supersaturation), Eq. (A7) captures the overall linear dependencies of the maximum supersaturation on instrument operating conditions reported by Roberts and Nenes (2005) and Lance et al. (2006).

\section{Appendix B}

\section{Single and double precision models}

As an example of improved model performance we ran one simulation using identical inputs for the original single precision (FORTRAN) model used in Lathem and Nenes (2011) and the same model converted to double precision accuracy. 


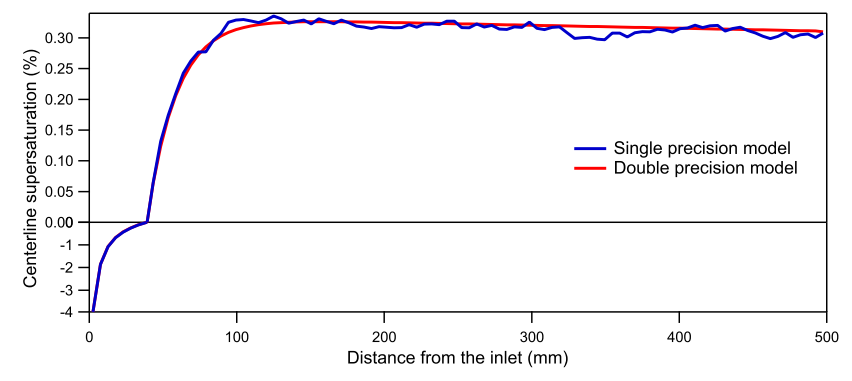

Fig. B1. Centerline supersaturation profiles from the single and double precision models after 1000 iterations. Note that there are different scales for sub- and supersaturated regions.

The inputs are: flow rate $0.5 \mathrm{Lmin}^{-1}$, pressure $500 \mathrm{mbar}$, sheath-to-aerosol flow ratio 10.0 , and column top and bottom temperatures $293 \mathrm{~K}$ and $301 \mathrm{~K}$, respectively. Dry particles are ammonium sulfate $(\kappa=0.6)$ divided into 50 size bins with $100 \mathrm{~nm}$ geometric mean diameter and 1.6 log-normal standard deviation. Particle concentration was set to $1 \mathrm{~cm}^{-3}$, but water vapor depletion effects were still calculated by updating the condensation sink (i.e. calculating droplet growth) after every 50 iterations. Scalar and vector fields were calculated for $100 \times 100$ grid spacing. Solver convergence criterion was set to machine precision, so that both models would perform the maximum allowed number of 1000 iterations. For the timing purposes discussed in the main text, calculations were also repeated with zero dry particle concentration, which means that droplet growth was not calculated. Calculated centerline supersaturation profiles for the $1 \mathrm{~cm}^{-3}$ concentration case are shown in Fig. B1.

Acknowledgements. We would like to thank funding support from the Finnish Cultural Foundation. We also acknowledge support from a NSF Graduate Student Fellowship, an NSF CAREER award, DOE Global Change Education Program, the DOE program STTR, NASA Earth and Space Science Graduate Research Fellowship, and NOAA. We thank G. Kok and R. Drgac from Droplet Measurement Technologies for their support and advice on calibration of the OPC. S. Lance and C. A. Brock are acknowledged for their help with the MIE calculations. We also thank the Langley Aerosol Group for their work on the ARCTAS campaign.

Edited by: J. H. Seinfeld

\section{References}

Asa-Awuku, A. and Nenes, A.: Effect of solute dissolution kinetics on cloud droplet formation: Extended Köhler theory, J. Geophys. Res., 112, D22201, doi:10.1029/2005JD006934, 2007.

Asa-Awuku, A., Engelhart, G. J., Lee, B. H., Pandis, S. N., and Nenes, A.: Relating CCN activity, volatility, and droplet growth kinetics of $\beta$-caryophyllene secondary organic aerosol, Atmos. Chem. Phys., 9, 795-812, doi:10.5194/acp-9-795-2009, 2009.
Asa-Awuku, A., Nenes, A., Gao, S., Flagan, R. C., and Seinfeld, J. H.: Water-soluble SOA from Alkene ozonolysis: composition and droplet activation kinetics inferences from analysis of CCN activity, Atmos. Chem. Phys., 10, 1585-1597, doi:10.5194/acp10-1585-2010, 2010.

Asa-Awuku, A., Moore, R. H., Nenes, A., Bahreini, R., Holloway, J. S., , Brock, C. A., Middlebrook, A. M., Ryerson, T. B., Jimenez, J. L., DeCarlo, P. F., Hecobian, A., Weber, R. J., Stickel, R., Tanner, D. J., and Huey, L. G.: Airborne cloud condensation nuclei measurements during the 2006 Texas Air Quality Study, J. Geophys. Res., 116, D11201, doi:10.1029/2010JD014874, 2011.

Bahadur, R. and Russell, L. M.: Water uptake coefficients and deliquescence of $\mathrm{NaCl}$ nanoparticles at atmospheric relative humidities from molecular dynamics simulations, J. Chem. Phys., 129, 094508, doi:10.1063/1.2971040, 2008.

Bohren, C. F. and Huffman, D. R.: Absorption and Scattering of Light by Small Particles, John Wiley and Sons, 1983.

Bougiatioti, A., Fountoukis, C., Kalivitis, N., Pandis, S. N., Nenes, A., and Mihalopoulos, N.: Cloud condensation nuclei measurements in the marine boundary layer of the Eastern Mediterranean: CCN closure and droplet growth kinetics, Atmos. Chem. Phys., 9, 7053-7066, doi:10.5194/acp-9-7053-2009, 2009.

Bougiatioti, A., Nenes, A., Fountoukis, C., Kalivitis, N., Pandis, S. N., and Mihalopoulos, N.: Size-resolved CCN distributions and activation kinetics of aged continental and marine aerosol, Atmos. Chem. Phys., 11, 8791-8808, doi:10.5194/acp-11-87912011, 2011.

Cerully, K. M., Raatikainen, T., Lance, S., Tkacik, D., Tiitta, P., Petäjä, T., Ehn, M., Kulmala, M., Worsnop, D. R., Laaksonen, A., Smith, J. N., and Nenes, A.: Aerosol hygroscopicity and CCN activation kinetics in a boreal forest environment during the 2007 EUCAARI campaign, Atmos. Chem. Phys., 11, 12369-12386, doi:10.5194/acp-11-12369-2011, 2011.

Chuang, P. Y.: Measurement of the timescale of hygroscopic growth for atmospheric aerosols, J. Geophys. Res., 108, 4282 doi:10.1029/2002JD002757, 2003.

Chuang, P. Y.: Sensitivity of cloud condensation nuclei activation processes to kinetic parameters, J. Geophys. Res., 111, D09201, doi:10.1029/2005JD006529, 2006.

Chuang, P. Y., Charlson, R. J., and Seinfeld, J. H.: Kinetic limitations on droplet formation in clouds, Nature, 390, 594-596, doi:10.1038/37576, 1997.

Clegg, S. L. and Brimblecombe, P.: Equilibrium partial pressures of strong acids over concentrated saline solutions - I. $\mathrm{HNO}_{3}$, Atmos. Environ., 22, 91-100, 1988.

Davidovits, P., Worsnop, D. R., Jayne, J. T., Kolb, C. E., Winkler, P., Vrtala, A., Wagner, P. E., Kulmala, M., Lehtinen, K. E. J., Vesala, T., and Mozurkewich, M.: Mass accommodation coefficient of water vapor on liquid water, Geophys. Res. Lett., 31, L22111, doi:10.1029/2004GL020835, 2004.

Davidovits, P., Kolb, C. E., Williams, L. R., Jayne, J. T., and Worsnop, D. R.: Mass Accommodation and Chemical Reactions at Gas-Liquid Interfaces, Chem. Rev., 106, 1323-1354, doi:10.1021/cr040366k, 2006.

Drisdell, W. S., Saykally, R. J., and Cohen, R. C.: On the evaporation of ammonium sulfate solution, P. Natl. Acad. Sci. USA, 106, 18897-18901, doi:10.1073/pnas.0907988106, 2009. 
Engelhart, G. J., Asa-Awuku, A., Nenes, A., and Pandis, S. N.: CCN activity and droplet growth kinetics of fresh and aged monoterpene secondary organic aerosol, Atmos. Chem. Phys., 8, 39373949, doi:10.5194/acp-8-3937-2008, 2008.

Engelhart, G. J., Moore, R. H., Nenes, A., and Pandis, S. N.: Cloud condensation nuclei activity of isoprene secondary organic aerosol, J. Geophys. Res., 116, D02207, doi:10.1029/2010JD014706, 2011.

Fukuta, N. and Walter, L. A.: Kinetics of Hydrometeor Growth from a Vapor-Spherical Model, J. Atmos. Sci., 27, 1160-1172, 1970.

IPCC: Climate Change 2007: The Physical Science Basis. Contribution of Working Group I to the Fourth Assessment Report of the Intergovernmental Panel on Climate Change, Cambridge University Press, Cambridge, UK and New York, NY, USA, 2007.

Jacob, D. J., Crawford, J. H., Maring, H., Clarke, A. D., Dibb, J. E., Emmons, L. K., Ferrare, R. A., Hostetler, C. A., Russell, P. B., Singh, H. B., Thompson, A. M., Shaw, G. E., McCauley, E., Pederson, J. R., and Fisher, J. A.: The Arctic Research of the Composition of the Troposphere from Aircraft and Satellites (ARCTAS) mission: design, execution, and first results, Atmos. Chem. Phys., 10, 5191-5212, doi:10.5194/acp-10-5191-2010, 2010.

Köhler, H.: The nucleus in and the growth of hygroscopic droplets, Trans. Faraday Soc., 32, 1151-1161, 1936.

Kolb, C. E., Cox, R. A., Abbatt, J. P. D., Ammann, M., Davis, E. J., Donaldson, D. J., Garrett, B. C., George, C., Griffiths, P. T., Hanson, D. R., Kulmala, M., McFiggans, G., Pöschl, U., Riipinen, I., Rossi, M. J., Rudich, Y., Wagner, P. E., Winkler, P. M., Worsnop, D. R., and O'Dowd, C. D.: An overview of current issues in the uptake of atmospheric trace gases by aerosols and clouds, Atmos. Chem. Phys., 10, 10561-10605, doi:10.5194/acp-1010561-2010, 2010.

Koop, T., Bookhold, J., Shiraiwa, M., and Pöschl, U.: Glass transition and phase state of organic compounds: dependency on molecular properties and implications for secondary organic aerosols in the atmosphere, Phys. Chem. Chem. Phys., 13, 19238-19255, doi:10.1039/C1CP22617G, 2011.

Kumar, P., Sokolik, I. N., and Nenes, A.: Measurements of cloud condensation nuclei activity and droplet activation kinetics of fresh unprocessed regional dust samples and minerals, Atmos. Chem. Phys., 11, 3527-3541, doi:10.5194/acp-11-35272011, 2011a.

Kumar, P., Sokolik, I. N., and Nenes, A.: Cloud condensation nuclei activity and droplet activation kinetics of wet processed regional dust samples and minerals, Atmos. Chem. Phys., 11, 8661-8676, doi:10.5194/acp-11-8661-2011, 2011 b.

Laaksonen, A., Vesala, T., Kulmala, M., Winkler, P. M., and Wagner, P. E.: Commentary on cloud modelling and the mass accommodation coefficient of water, Atmos. Chem. Phys., 5, 461-464, doi:10.5194/acp-5-461-2005, 2005.

Lance, S., Medina, J., Smith, J. N., and Nenes, A.: Mapping the Operation of the DMT Continuous Flow CCN Counter, Aerosol Sci. Tech., 40, 242-254, doi:10.1080/02786820500543290, 2006.

Lance, S., Nenes, A., Mazzoleni, C., Dubey, M. K., Gates, H., Varutbangkul, V., Rissman, T. A., Murphy, S. M., Sorooshian, A., Flagan, R. C., Seinfeld, J. H., Feingold, G., and Jonsson, H. H.: Cloud condensation nuclei activity, closure, and droplet growth kinetics of Houston aerosol during the Gulf of Mexico Atmospheric Composition and Climate Study (GoMACCS), J. Geo- phys. Res., 114, D00F15, doi:10.1029/2008JD011699, 2009.

Lathem, T. L. and Nenes, A.: Water Vapor Depletion in the DMT Continuous-Flow CCN Chamber: Effects on Supersaturation and Droplet Growth, Aerosol Sci. Tech., 45, 604-615, doi:10.1080/02786826.2010.551146, 2011.

Lathem, T. L., Beyersdorf, A. J., Thornhill, L., Winstead, E., Cubison, M. J., Hecobian, A., Jimenez, J. L., Weber, R. J., Anderson, B. E., and Nenes, A.: Analysis of CCN activity and droplet activation kinetics of Arctic aerosol during summer 2008, in preparation, 2012.

Li, Y. Q., Davidovits, P., Kolb, C. E., and Worsnop, D. R.: Mass and Thermal Accommodation Coefficients of $\mathrm{H} 2 \mathrm{O}(\mathrm{g})$ on Liquid Water as a Function of Temperature, J. Phys. Chem. A, 105, 10627-10634, doi:10.1021/jp012758q, 2001.

McNaughton, C. S., Clarke, A. D., Howell, S. G., Pinkerton, M., Anderson, B., Thornhill, L., Hudgins, C., Winstead, E., Dibb, J. E., Scheuer, E., and Maring, H.: Results from the DC-8 Inlet Characterization Experiment (DICE): Airborne Versus Surface Sampling of Mineral Dust and Sea Salt Aerosols, Aerosol Sci. Tech., 41, 136-159, doi:10.1080/02786820601118406, 2007.

Moore, R. H. and Nenes, A.: Scanning Flow CCN Analysis A Method for Fast Measurements of CCN Spectra, Aerosol Sci. Tech., 43, 1192-1207, doi:10.1080/02786820903289780, 2009.

Moore, R. H., Ingall, E. D., Sorooshian, A., and Nenes, A.: Molar mass, surface tension, and droplet growth kinetics of marine organics from measurements of CCN activity, Geophys. Res. Lett., 35, L07801, doi:10.1029/2008GL033350, 2008.

Moore, R. H., Nenes, A., and Medina, J.: Scanning Mobility CCN Analysis - A Method for Fast Measurements of Size-Resolved CCN Distributions and Activation Kinetics, Aerosol Sci. Tech., 44, 861-871, doi:10.1080/02786826.2010.498715, 2010.

Moore, R. H., Raatikainen, T., Langridge, J. M., Bahreini, R., Brock, C. A., Holloway, J. S., Lack, D., Middlebrook, A. M., Perring, A. E., Schwarz, J. P., Spackman, J. R., and Nenes, A.: CCN Spectra, Hygroscopicity, and Droplet Activation Kinetics of Secondary Organic Aerosol Resulting from the 2010 Deepwater Horizon Oil Spill, Environ. Sci. Technol., 46, 3093-3100, doi:10.1021/es203362w, 2012.

Mozurkewich, M.: Aerosol Growth and the Condensation Coefficient for Water: A Review, Aerosol Sci. Tech., 5, 223-236, 1986.

Murphy, S. M., Agrawal, H., Sorooshian, A., Padró, L. T., Gates, H., Hersey, S., Welch, W. A., Jung, H., Miller, J. W., Cocker, D. R., Nenes, A., Jonsson, H. H., Flagan, R. C., and Seinfeld, J. H.: Comprehensive Simultaneous Shipboard and Airborne Characterization of Exhaust from a Modern Container Ship at Sea, Environ. Sci. Technol., 43, 4626-4640, doi:10.1021/es802413j, 2009.

Nenes, A., Ghan, S., Abdul-Razzak, H., Chuang, P. Y., and Seinfeld, J. H.: Kinetic limitations on cloud droplet formation and impact on cloud albedo, Tellus B, 53, 133-149, doi:10.1034/j.16000889.2001.d01-12.x, 2001.

Nenes, A., Charlson, R. J., Facchini, M. C., Kulmala, M., Laaksonen, A., and Seinfeld, J. H.: Can chemical effects on cloud droplet number rival the first indirect effect?, Geophys. Res. Lett., 29, 1848, doi:10.1029/2002GL015295, 2002.

Padró, L. T., Tkacik, D., Lathem, T., Hennigan, C. J., Sullivan, A. P., Weber, R. J., Huey, L. G., and Nenes, A.: Investigation of cloud condensation nuclei properties and droplet growth kinetics of the 
water-soluble aerosol fraction in Mexico City, J. Geophys. Res., 115, D09204, doi:10.1029/2009JD013195, 2010.

Padró, L. T., Moore, R. H., Zhang, X., Rastogi, N., Weber, R. J., and Nenes, A.: Mixing state and compositional effects on CCN activity and droplet growth kinetics of size-resolved $\mathrm{CCN}$ in an urban environment, Atmos. Chem. Phys. Discuss., 11, 3272332768, doi:10.5194/acpd-11-32723-2011, 2011.

Petters, M. D. and Kreidenweis, S. M.: A single parameter representation of hygroscopic growth and cloud condensation nucleus activity, Atmos. Chem. Phys., 7, 1961-1971, doi:10.5194/acp-71961-2007, 2007.

Pitzer, K. S. and Mayorga, G.: Thermodynamics of electrolytes. II. Activity and osmotic coefficients for strong electrolytes with one or both ions univalent, J. Phys. Chem., 77, 2300-2308, doi:10.1021/j100638a009, 1973.

Roberts, G. C. and Nenes, A.: A Continuous-Flow Streamwise Thermal-Gradient CCN Chamber for Atmospheric Measurements, Aerosol Sci. Tech., 39, 206-221, doi:10.1080/027868290913988, 2005.

Rose, D., Gunthe, S. S., Mikhailov, E., Frank, G. P., Dusek, U., Andreae, M. O., and Pöschl, U.: Calibration and measurement uncertainties of a continuous-flow cloud condensation nuclei counter (DMT-CCNC): CCN activation of ammonium sulfate and sodium chloride aerosol particles in theory and experiment, Atmos. Chem. Phys., 8, 1153-1179, doi:10.5194/acp-8-11532008, 2008.

Ruehl, C. R., Chuang, P. Y., and Nenes, A.: How quickly do cloud droplets form on atmospheric particles?, Atmos. Chem. Phys., 8, 1043-1055, doi:10.5194/acp-8-1043-2008, 2008.

Ruehl, C. R., Chuang, P. Y., and Nenes, A.: Distinct CCN activation kinetics above the marine boundary layer along the California coast, Geophys. Res. Lett., 36, L15814, doi:10.1029/2009GL038839, 2009.

Seinfeld, J. H. and Pandis, S. N.: Atmospheric chemistry and physics: from air pollution to climate change, Wiley, New York, USA, 1998.

Shantz, N. C., Chang, R. Y.-W., Slowik, J. G., Vlasenko, A., Abbatt, J. P. D., and Leaitch, W. R.: Slower CCN growth kinetics of anthropogenic aerosol compared to biogenic aerosol observed at a rural site, Atmos. Chem. Phys., 10, 299-312, doi:10.5194/acp10-299-2010, 2010.
Shaw, R. A. and Lamb, D.: Experimental determination of the thermal accommodation and condensation coefficients of water, J. Chem. Phys., 111, 10659-10663, doi:10.1063/1.480419, 1999.

Sjogren, S., Gysel, M., Weingartner, E., Baltensperger, U., Cubison, M., Coe, H., Zardini, A., Marcolli, C., Krieger, U., and Peter, T.: Hygroscopic growth and water uptake kinetics of two-phase aerosol particles consisting of ammonium sulfate, adipic and humic acid mixtures, J. Aerosol Sci., 38, 157-171, doi:10.1016/j.jaerosci.2006.11.005, 2007.

Takahama, S. and Russell, L. M.: A molecular dynamics study of water mass accommodation on condensed phase water coated by fatty acid monolayers, J. Geophys. Res., 116, D02203, doi:10.1029/2010JD014842, 2011.

Tong, H.-J., Reid, J. P., Bones, D. L., Luo, B. P., and Krieger, U. K.: Measurements of the timescales for the mass transfer of water in glassy aerosol at low relative humidity and ambient temperature, Atmos. Chem. Phys., 11, 4739-4754, doi:10.5194/acp-11-47392011, 2011.

Virtanen, A., Joutsensaari, J., Koop, T., Kannosto, J., Yli-Pirilä, P., Leskinen, J., Mäkelä, J. M., Holopainen, J. K., Pöschl, U., Kulmala, M., Worsnop, D. R., and Laaksonen, A.: An amorphous solid state of biogenic secondary organic aerosol particles, Nature, 467, 824-827, doi:10.1038/nature09455, 2010.

Winkler, P. M., Vrtala, A., Wagner, P. E., Kulmala, M., Lehtinen, K. E. J., and Vesala, T.: Mass and Thermal Accommodation during Gas-Liquid Condensation of Water, Phys. Rev. Lett., 93, 075701, doi:10.1103/PhysRevLett.93.075701, 2004.

Winkler, P. M., Vrtala, A., Rudolf, R., Wagner, P. E., Riipinen, I., Vesala, T., Lehtinen, K. E. J., Viisanen, Y., and Kulmala, M.: Condensation of water vapor: Experimental determination of mass and thermal accommodation coefficients, J. Geophys. Res., 111, D19202, doi:10.1029/2006JD007194, 2006.

Zientara, M., Jakubczyk, D., Derkachov, G., Kolwas, K., and Kolwas, M.: Simultaneous determination of mass and thermal accommodation coefficients from temporal evolution of an evaporating water microdroplet, J. Phys. D Appl. Phys., 38, 1978, 2005.

Zobrist, B., Marcolli, C., Pedernera, D. A., and Koop, T.: Do atmospheric aerosols form glasses?, Atmos. Chem. Phys., 8, 52215244, doi:10.5194/acp-8-5221-2008, 2008. 